\title{
ALLEVIATION OF STRESS CONCENTRATION \\ WITH ANALOGUE REINFORCEMENT
}

by

\section{Toshiaki Chiba}

Thesis submitted to the Graduate Faculty of the Virginia Polytechnic Institute and State University in partial fulfillment of the requirements for the degree of

\author{
MASTER OF SCIENCE
}

in

Engineering Mechanics

APPROVED:

R. A. Heller, Chairman

D. Frederick

H. F. Brinson

March, 1972

Blacksburg, Virginia 
ACKNOWLEDGMENTS

The author wishes to express his sincere appreciation to Dr. R. A. Heller for his invaluable guidance, encouragement, and criticism during both the research phase and the preparation for this thesis.

The author would also like to extend his thanks to the members of his committee, Professors Frederick and Brinson, and to

for the advice.

The author is grateful also to

and

, who not only performed machining and modification work, but also furnished the author with valuable advice, and to for typing the manuscript.

This research was supported by the Department of Defense, Project THEMIS, Contract Number with Watervliet Arsena?, Watervliet, New York. 


\section{CONTENTS}

ACKNOWLEDGMENTS ..................... i

LIST OF FIGURES ...................... iv

LIST OF SYMBOLS .................

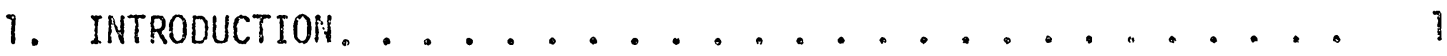

2. LITERATURE REVIEW ................... 2

3. THE EXPERIMENT. ................ 8

3.1 Determination of Stress Trajectories ....... 8

3.2 Photofabrication Method. ........... 14

3.3 Specimen Geometry and Photoelastic Test Procedure. . . . 20

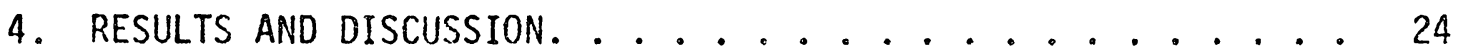

5. CONCLUSIONS AND RECORMENDATIONS ............ 31

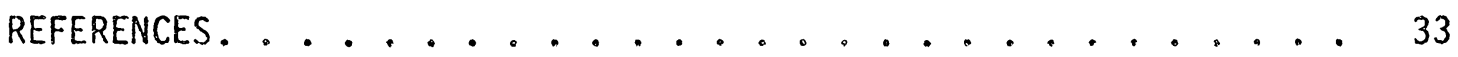

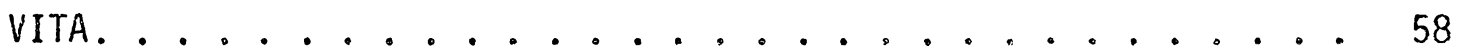




\section{LIST OF FIGURES}

1. Stresses in Polar Coordinates around a Circular Hole for a Bar in Tension ............ 36

2. Various Types of Reinforcing Rings ............ 37

3. Test Specimens of Hyman. . . . . . . . . . . 38

4. Process of Photofabrication. ........... 39

5. Apparatus for Exposure in Photofabrication ........ 40

6. Reaction Products in Etching Procedure .......... 41

7. Specimen Geometry. ............... 42

8. Photograph of Specimens A, B, C and D......... 43

9. Loading Device . . . . . . . . . . . . . 44

10. Fringe Pattern of Specimen A . . . . . . . . 45

11. Fringe Pattern of Specimen B . . . . . . . . . 46

12. Fringe Pattern of Specimen C . . . . . . . . 47

13. Fringe Pattern of Specimen D.......... 48

14. Stress Distributions in Specimen A.......... 49

15. Stress Distributions in Specimen B .......... 50

16. Stress Distributions in Specimen C . . . . . . . 51

17. Stress Distributions in Specimen D . . . . . . . 52

18. Stress Distributions in Specimen P......... 53

19. Stress Distributions in Specimen A'.......... 54

20. Stress Distributions in Specimen B'.......... 55

21. Comparison with the Experimental Results of Daniel and Rowlands and with the Theoretical Value for an Isotropic Plate................ 56

22. Comparison with Experimental Results of Suzuki ...... 57 
LIST OF SYMBOLS

$\begin{array}{ll}\sigma_{r}, \sigma_{\theta}, \tau_{r \theta} & \text { Stress components in polar coordinates } \\ \sigma_{x}, \sigma_{y}, \tau_{x y} & \text { Stress components in cartesian coordinates } \\ \sigma_{1}, \sigma_{2} & \text { Principal stresses } \\ \sigma_{a} & \text { Average stress applied at the end of the plate } \\ \sigma_{0} & \begin{array}{l}\text { Average stress on the transverse section of symmetry } \\ \text { through a hole }\end{array} \\ a, b & \text { Radius of hole and half width of the plate, respectively } \\ r, \theta & \text { Polar coordinates } \\ K_{t} & \text { Stress concentration factor in tension } \\ f & \text { Material fringe value } \\ n & \text { Fringe order } \\ t & \text { Plate thickness } \\ \alpha & \text { Angle between principal direction and } x \text { axis } \\ \phi & \text { Airey's stress function } \\ R_{1}, R_{2} & \text { Inner and outer radii of a reinforcing ring, respectively } \\ h_{1}, h_{2} & \begin{array}{l}\text { Total thickness of reinforced and unreinforced plate, } \\ \text { respectively }\end{array} \\ E_{L}, E_{T} & \begin{array}{l}\text { Elastic moduli in the longitudinal and transverse } \\ \text { directions, respectively }\end{array} \\ v_{L T} & \begin{array}{l}\text { Poisson's ratio } \\ G_{L}\end{array}\end{array}$




\section{INTRODUCTION}

Several researchers have investigated the problem of reducing stress concentration around a hole in a plate. The most frequently utilized technique involves the use of a bead or a reinforcing ring around the hole.

Recent interest in filamentary composites has focused attention on the possibilities of improving the distribution of stresses with variations of the density, stiffness and orientation of fibers in the immediate vicinity of a stress raiser.

With this viewpoint in mind reinforced plates were constructed in which the reinforcement was placed either in the form of a rectangular grid or along an orthogonal set of lines following stress trajectories in the plate.

The reinforcement in these specimens consisted of a photo-etched brass grid sandwiched between two sheets of a birefringent material.

Stress concentration factors were then determined photoelastically and were compared with theoretical and experimental values for isotropic homogeneous plates as well with published experimental results for fiber reinforced and bead reinforced plates.

A substantial reduction of the stress concentration factor was observed in plates containing the "analogue" reinforcement (fibers following stress trajectories). 


\section{LITERATURE REVIEW}

Determination of stress concentration at the edge of a hole is of great practical importance in engineering structures.

The analytical solution of this problem may be traced to the solution of the stress distribution in an infinite plate with a hole under a uniform load first published by Kirsch [1] in 1898. According to that paper,

$$
\begin{aligned}
& \sigma_{r}=\frac{\sigma_{a}}{2}\left(1-\frac{a^{2}}{r^{2}}\right)+\frac{\sigma_{a}}{2}\left(1-\frac{4 a^{2}}{r^{2}}+\frac{3 a^{4}}{r^{4}}\right) \cos 2 \theta \\
& \sigma_{\theta}=\frac{\sigma_{a}}{2}\left(1+\frac{a^{2}}{r^{2}}\right)-\frac{\sigma_{a}}{2}\left(1+\frac{3 a^{4}}{r^{4}}\right) \cos 2 \theta \\
& \tau_{r \theta}=-\frac{\sigma_{a}}{2}\left(1+\frac{2 a^{2}}{r^{2}}-\frac{3 a^{4}}{r^{4}}\right) \sin 2 \theta,
\end{aligned}
$$

with the notation shown in Fig. 1. As noted by Timoshenko and Goodier [2], this solution has been well confirmed many times by strain measurements and by photoelastic experiments.

In 1930, Howland [3] extended the solution to the more general case. In his work, the plate was assumed to be bounded by two parallel edges, with a hole midway between these edges. The analysis was developed for the case of a stress system symmetrical with respect to the longitudinal axis of the strip and to the diameter of the hole perpendicular to the axis. The solution of the uniaxial tension problem was then obtained by successive approximations. 
From Eq. $(1-1)$, it is seen that $\sigma_{\theta}$ is greatest when $\theta=\pi / 2$ or $\theta=3 \pi / 2$, i.e., at the ends $m$ and $n$ of the diameter perpendicular to the direction of the applied force. At these points $\left(\sigma_{\theta}\right)_{\max }=3 \sigma_{a}$. This is the maximum tensile stress and is three times the uniform stress $\sigma_{a}$, applied at remote point from the hole.

The stress concentration factor is defined as the ratio of the maximum stress and the remote, uniform stress,

$$
k_{t}=\frac{\sigma_{\max }}{\sigma_{a}}
$$

For an infinite plate with a hole under uniform tension, $k_{t}=3$. It is often necessary to reduce the stress concentration around holes in structures. This can be done by adding a bead or reinforcing ring to the plate. An approximate solution for this problem was given as early as 1924 , by Timoshenko [4], who treated the reinforcement as a curved bar. The method is applicable to reinforcement of arbitrary cross section, provided its cross-sectional dimensions are small compared with the radius of the hole.

In 1932, Sezawa and Kubo [5] published a plane-stress solution for reinforcement by a symmetrical circular doubler in which the reinforced plate is replaced by an equivalent plate of constant thickness but with the elastic modulus larger within the doubler than through the rest of the plate. In 1938, another solution for reinforcement by a symmetrical circular doubler was published by Gurney [6]. Gurney's solution proceeds from the known general plane-stress solution for an 
infinite plate with a circular hole and adjusts the arbitrary constants in the solution to satisfy equilibrium of forces and continuity of displacements at the outer edge of the reinforcement. An extension of Gurney's solution to include the additional effect of a flange around the edge of the hole was given in 1944, by Beskin [7]. In Beskin's solution, the stresses in the doubler and the plate are computed from plane-stress theory on the assumption that the flange at the edge of the hole carries circumferential stresses only. The solutions either require the reinforcement to be concentrated near the edge of the hole (Timoshenko, Beskin), or require the reinforcement to be of constant thickness (Sezawa and Kubo, Gurney). In 1948, an analys is of radially symmetrical reinforcements of variable thickness was given by Levy, McPherson and Smith [8] for the case in which the load is uniform tension in all directions. In 1955, Radok [9] presented a two-dimensional solution for the elastic equilibrium of an infinite thin plate with a compactly reinforced hole. Radok's work utilized the general techniques developed by Muskhelishvili [10] for the solution of two dimensional elasto-static problems and represented a concise, direct method applicable to any hole which could be mapped conformally onto the unit circle by use of polynomials or rational functions.

In the field of experimental research, Shimada [11] reported the stress distributions in epoxy-resin bars with reinforced circular holes under pure tension. The holes were reinforced by bonding aluminum rings to the bars inside the holes as shown in Fig. 2(a). Various proportions of circular reinforcements and different width of bars were investigated, 
and the stress distributions were determined photoelastically in the epoxy-resin part of the bar. Suzuki [12] measured the stress distributions photoelastically along the inner surface of a ring under uniform tension. He used materials with nearly equal Young's moduli in the plate and the ring. Thus, the specimen was considered to be one solid body. His reinforcing rings are shown in Fig. 2(b). In 1969, the same author, Suzuki [13], investigated the stress distribution around a reinforced circular hole, Fig. 2(b), in an infinite plate subjected to uniaxial tension. Plates were made of aluminum with reinforcing rings of aluminum, brass, copper and mild steel. The stresses were obtained by least-square method and stress concentration factors were decided. Additional work for the determination of the stress distribution around a circular hole was performed in 1964 and 1967 by Seika [14],[15]. His reinforcing rings are shown in Figs. $2(c)$ and $(d)$. To determine the stress distribution, he used the photoelastic stress freezing method.

Recently, studies of fiber reinforced composite materials have been investigated. Daniel and Rowlands [16] determined the strain and the stress concentration factor by the moire technique. The specimens used in their investigation were 7-ply glass-epoxy laminates of $[90 / 0 / 90 / \overline{0}]_{S}$ layup, with approximately 0.45 volume fraction of fibers (Scotchply 1002, 3M Company). The specimens were $4 \mathrm{in}$. wide and 0.067 in. thick with central circular holes of $0.50 \mathrm{in}, 0.75 \mathrm{in.}$, and 1.00 in. diameter. These specimens were loaded in tension in increments of 300 ibs. up to levels of 2,700 and $3,900 \mathrm{lb}$. The results of this investigation will be discussed in Chapter 4 . 
When a composite under various loading conditions is considered, discussions shift from a material to a structural viewpoint. Since a composite is a combination of materials selected to obtain specified design objectives, a structural mechanics approach is essential. If the roles of the constituent elements of a composite are reconsidered, new approaches to reducing stress concentrations may be found.

As noted by Gerard [17], in 1967, a laminate can be designed to carry an alternate load system in addition to the basic biaxial load $\left(N_{1}\right.$ and $\left.N_{2}\right)$ for which it was primarily designed. He also suggested that one could pose the design question: given a filamentary bilayer laminate designed for the principal stress resultants $N_{1}$ and $N_{2}$, what are other possible load combinations that the laminate can carry?

In 1969, two years after Gerard's suggestion, Hyman [18] reported exploratory test results on fiber reinforced plate with circular holes under tension in which the reinforcement was supposed to approximate the directions of principal stress resultants. Since the plates, as shown in Fig. 3, were fabricated by simply separating the fibers around the hole, their orientation did not really coincide with the orientation of the principal stress resultants. Hyman's results will be discussed in Chapter 4.

Lackman and Ault [19] investigated the effects of fiber orientation on the stress distribution around a cut-out in a filamentary composite plate. Using a finite element analysis they have concluded that varying the direction and shape of the reinforcement results in a significant reduction of the stress concentration. They examined plates with 
rectangular cut-outs and lugs with circular holes. Since they limited their choices of reinforcement to $0^{\circ}, 0-90^{\circ}$ and isotropic stiffening, comparisons with the present investigation are only qualitative. 


\section{THE EXPERIMENT}

Specimens used in this investigation were made by sandwiching brass reinforcement between two birefringent plates. Depending on the type of reinforcement, these specimens are classified into two categories. The first type of reinforcement follows the stress trajectories of an infinite plate with a half inch hole, while the second type consists of a rectangular grid of straight lines.

It is difficult to produce such reinforcement by punching techniques or other mechanical means. Mechanical techniques can result in various side effects, such as residual stresses or excessive deformations especially when very thin, very brittle, or very soft materials are being processed. With chemical milling and Kodak "photosensitive resists" [20],[21], these problems are greatly reduced. For this reason, a photofabrication method was used to shape the reinforcement into the desired configurations.

\subsection{Determination of Stress Trajectories}

The stress distribution for an infinite plate with a hole under an uniaxial tensile load is expressed in cylindrical coordinates as shown in Eqs. (1-1). In order to determine the stress trajectories, Eqs. (1-1) are expressed in rectangular cartesian form.

A thin plate under a uniaxial tensile load, as shown in Fig. I, will be analyzed. If the width, $2 b$, of the plate is large in comparison with the radius, $a$, of the hole, the stresses at a radius, $b$, are 
effectively the same as in the plate without the hole and are therefore given by

$$
\begin{aligned}
& \left(\sigma_{r}\right)_{r=b}=\sigma_{a} \cos ^{2} \theta=\frac{1}{2} \sigma_{a}(1+\cos 2 \theta) \\
& \left(\tau_{r \theta}\right)_{r=b}=-\frac{1}{2} \sigma_{a} \sin 2 \theta
\end{aligned}
$$

These forces, acting around the outside of the ring having inner and outer radii $r=a$ and $r=b$ respectively, produce a stress distribution within the ring which may be regarded as consisting of two parts. The first part is due to the constant component $\frac{1}{2} \sigma_{a}$ of the uniaxial forces. The remaining part consists of the normal force $\frac{1}{2} \sigma_{a} \cos 2 \theta$, together with the shearing force $-\frac{1}{2} \sigma_{a} \sin 2 \theta$.

First the stresses produced by the uniform tension, $\frac{1}{2} \sigma_{2}$, acting on the outer boundary $(r=b)$ will be determined. Since the $z$ axis normal to the plane of the plate is a symmetry axis, the stress function in this case is given by (2)

$$
\phi_{1}=A \log r+B r^{2} \log r+C r^{2}+0 \text {, }
$$

where $A, B, C$ and $D$ are constants of integration. Because of axial symmetry, all derivatives with respect to $\theta$ are zero, and consideration of finite displacements requires, for a unique solution, that $B=0$. Hence, the stress function for the case of no internal forces becomes

$$
\phi_{1}=-\frac{a^{2} b^{2} \sigma_{a}}{2\left(b^{2}-a^{2}\right)} \log r+\frac{b^{2} r^{2} \sigma_{a}}{4\left(b^{2}-a^{2}\right)} .
$$


Since $r^{2}=x^{2}+y^{2}$, the stress function, $\phi_{1}$, can be written in cartesian coordinate form as

$$
\phi_{1}=-\frac{a^{2} b^{2} \sigma_{a}}{2\left(b^{2}-a^{2}\right)} \log \left(x^{2}+y^{2}\right)^{1 / 2}+\frac{b^{2} \sigma_{a}}{4\left(b^{2}-a^{2}\right)}\left(x^{2}+y^{2}\right) .
$$

Putting $a / b=0$, for the infinitely large plate,

$$
\phi_{1}=-\frac{a^{2} \sigma_{a}}{2} \log \left(x^{2}+y^{2}\right)^{1 / 2}+\frac{\sigma_{a}}{4}\left(x^{2}+y^{2}\right) .
$$

The stress components are given by

$$
\sigma_{x}=\frac{\partial^{2} \phi}{\partial y^{2}}, \quad \sigma_{y}=\frac{\partial^{2} \phi}{\partial x^{2}}, \quad \tau_{x y}=-\frac{\partial^{2} \phi}{\partial x^{2} \partial y} .
$$

The stress components due to the uniform tension $\frac{1}{2} \sigma_{a}$ on the outer boundary can be obtained from Eqs. (3-5) and (3-6)

$$
\begin{aligned}
& \sigma_{x}^{\prime}=-\frac{a^{2} \sigma_{a}}{2} \frac{x^{2}-y^{2}}{\left(x^{2}+y^{2}\right)^{2}}+\frac{\sigma_{a}}{2} \\
& \sigma_{y}^{\prime}=-\frac{a^{2} \sigma_{a}}{2} \frac{y^{2}-x^{2}}{\left(x^{2}+y^{2}\right)^{2}}+\frac{\sigma_{a}}{2} \\
& \tau_{x y}^{\prime}=-\frac{a^{2} \sigma_{a} x y}{\left(x^{2}+y^{2}\right)^{2}}
\end{aligned}
$$

The stress function for the second case, i.e., normal force $\frac{1}{2} \sigma_{a}$ $\cos 2 \theta$ and shearing force $-\frac{1}{2} \sigma_{a} \sin 2 \theta$ on the outer boundary $(r=b)$ is (2) 


$$
\phi_{2}=-\frac{\sigma}{4}\left[r^{2}+\frac{a^{4}}{r^{2}}-2 a^{2}\right] \cos 2 \theta
$$

Changing the stress function, $\phi_{2}$, into rectangular cartesian form by using the relationships

$$
r^{2}=x^{2}+y^{2} \text { and } \cos 2 \theta=\cos ^{2} \theta-\sin ^{2} \theta=\frac{x^{2}-y^{2}}{x^{2}+y^{2}} \text {, }
$$

and after setting $a / b \rightarrow 0, \phi_{2}$ can be written as

$$
\phi_{2}=-\frac{\sigma}{4}\left[x^{2}-y^{2}+\frac{a^{4}\left(x^{2}-y^{2}\right)}{\left(x^{2}+y^{2}\right)^{2}}-\frac{2 a^{2}\left(x^{2}-y^{2}\right)}{x^{2}+y^{2}}\right]
$$

From Eqs. (3-6) and (3-9), the stress components then become

$$
\begin{aligned}
& \sigma_{x}^{\prime \prime}=\frac{\sigma_{a}}{2}\left[1+\frac{a^{4}\left(3 x^{2}-y^{2}\right)}{\left(x^{2}+y^{2}\right)^{3}}-\frac{4 a^{2} x^{2}}{\left(x^{2}+y^{2}\right)^{2}}-\frac{4 a^{4} y^{2}\left(5 x^{2}-y^{2}\right)}{\left(x^{2}+y^{2}\right)^{4}}+\frac{16 a^{2} x^{2} y^{2}}{\left(x^{2}+y^{2}\right)^{3}}\right] \\
& \sigma_{y}^{\prime \prime}=-\frac{\sigma_{a}}{2}\left[1-\frac{a^{4}\left(x^{2}-3 y^{2}\right)}{\left(x^{2}+y^{2}\right)^{3}}-\frac{4 a^{2} y^{2}}{\left(x^{2}+y^{2}\right)^{2}}+\frac{4 a^{4} x^{2}\left(x^{2}-5 y^{2}\right)}{\left(x^{2}+y^{2}\right)^{4}}+\frac{16 a^{2} x^{2} y^{2}}{\left(x^{2}+y^{2}\right)^{3}}\right] \\
& \tau_{x y}^{\prime \prime}=2 a^{2} x y \sigma_{a}\left[\frac{x^{2}-y^{2}}{\left(x^{2}+y^{2}\right)^{3}}\right]\left[\frac{3 a^{2}}{\left(x^{2}+y^{2}\right)}-2\right]
\end{aligned}
$$

The total solution for the infinite plate with a hole under a uniaxial tensile load can be obtained by adding Eqs. (3-7) and (3-10) 
$\sigma_{x}=\frac{\sigma}{2}\left[2-\frac{a^{2}\left(5 x^{2}-y^{2}\right)}{\left(x^{2}+y^{2}\right)^{2}}+\frac{a^{4}\left(3 x^{2}-y^{2}\right)}{\left(x^{2}+y^{2}\right)^{3}}+\frac{16 a^{2} x^{2} y^{2}}{\left(x^{2}+y^{2}\right)^{3}}-\frac{4 a^{4} y^{2}\left(5 x^{2}-y^{2}\right)}{\left(x^{2}+y^{2}\right)^{4}}\right]$

$\sigma_{y}=\frac{\sigma_{a}}{2}\left[\frac{a^{2}\left(3 y^{2}+x^{2}\right)}{\left(x^{2}+y^{2}\right)^{2}}+\frac{a^{4}\left(x^{2}-3 y^{2}\right)}{\left(x^{2}+y^{2}\right)^{3}}-\frac{16 a^{2} x^{2} y^{2}}{\left(x^{2}+y^{2}\right)^{3}}-\frac{4 a^{4} x^{2}\left(x^{2}-5 y^{2}\right)}{\left(x^{2}+y^{2}\right)^{4}}\right]$

$\tau_{x y}=2 a^{2} x y \sigma_{a}\left\{\left[\frac{x^{2}-y^{2}}{\left(x^{2}+y^{2}\right)^{3}}\right]\left(\frac{3 a^{2}}{x^{2}+y^{2}}-2\right)-\frac{1}{2\left(x^{2}+y^{2}\right)^{2}}\right\}$

Eqs. (3-11) satisfy the following boundary conditions,

$$
\begin{aligned}
& \left.\sigma_{x}\right|_{\substack{x=a \\
y=0}}=0,\left.\quad \sigma_{x}\right|_{\substack{x=b \\
y=0}}=S,\left.\quad \sigma_{x}\right|_{\substack{x=0 \\
y=a}}=3 S \\
& \left.\sigma_{y}\right|_{\substack{y=a \\
x=0}}=0, \quad \sigma_{\substack{x=0 \\
y=b}}=0, \quad \sigma_{\substack{x=0 \\
y=0}}=-S \\
& \tau_{x y}=0 \text { at } x=0 \text { or } y=0 .
\end{aligned}
$$

To check the above results the following stress invariants were used

$$
\begin{aligned}
I & =\sigma_{x}+\sigma_{y}+\sigma_{z} \\
I I & =\sigma_{x y} \sigma+\sigma_{y} \sigma z+\sigma_{x} \sigma_{z}-\tau_{x y}^{2}-\tau_{y z}^{2}-\tau_{x z}^{2} \\
\text { III } & =\sigma_{x} \sigma_{y} \sigma_{z}+2 \tau_{x y} \tau_{y z} \tau_{x z}-\sigma_{x} \tau_{y z}^{2}-\sigma_{y} \tau_{x z}^{2}-\sigma_{z} \tau_{x y}^{2}
\end{aligned}
$$

Eqs. $(1-1)$ and Eqs. (3-11) were compared with the aid of Eqs. (3-13). 
Principal stress directions in a two dimensional state of stress are given by [22]

$$
\tan 2 \alpha=\frac{2 \tau x y}{\sigma_{x}-\sigma_{y}}
$$

where $\alpha$ is the angle between the principal direction and the $x$ axis. Since

$$
\begin{aligned}
& \tan 2 \alpha=\frac{2 \tan \alpha}{1-\tan ^{2} \alpha}, \\
& \frac{2 \tan \alpha}{1-\tan ^{2} \alpha}=\frac{2 \tau_{x y}}{\sigma_{x}-\sigma_{y}} .
\end{aligned}
$$

Hence,

$$
\tau_{x y} \tan ^{2} \alpha+\left(\sigma_{x}-\sigma_{y}\right) \tan \alpha-\tau_{x y}=0
$$

Solving this quadratic equation with respect to $\tan \alpha$, the slope of the stress trajectories is obtained:

$$
\tan \alpha=\frac{d y}{d x}=\frac{1}{\tau_{x y}}\left[-\left(\frac{\sigma_{x}-\sigma_{y}}{2}\right) \pm \sqrt{\left(\frac{\sigma_{x}-\sigma_{y}}{2}\right)^{2}+\tau_{x y}^{2}}\right] .
$$

In this equation, $\sigma_{x}, \sigma_{y}$ and $\tau_{x y}$ are given by Eqs. $(3-11)$.

From Eqs. $(3-11)$ and $(3-16)$ it is obvious that Eq. $(3-16)$ is

independent of the average stress $\sigma_{a}$. Therefore, Eqs. (3-11) were used without $\sigma_{a}$. 
To determine the stress trajectories, consisting of a family of orthogonal lines, the first order ordinary differential equation, Eq. (3-16), was first integrated numerically with a positive sign before the root and subsequently with a negative sign. The above integration was carried numerically by computer using a subroutine RKGS, which uses a Runge-Kutta method for an approximate solution of a system of first order ordinary differential equations with given initial values.

The numerical calculation was performed for a plate with a hole radius, $a$, of $0.5 \mathrm{in}$. Lower and upper bounds of the integration intervais for the independent variable were set at -2.5 and -0.001 respectively, and the initial increment of the independent variable was 0.125 . The starting point for the dependent variable was set at 0.125 and its increment was 0.125 .

The computed spacing of the stress trajectories is twice as large as the actual spacing of the reinforcement. As will be explained in section 3.2 the desired size of reinforcement was obtained by a photographic reduction.

\subsection{Photofabrication Method}

In engineering applications or in consumer markets, the concepts of photofabrication are widely used. This photofabrication is a unique process by which parts can be produced through the use of photography and photosensitive materials called "resists".

This technique of photofabrication can be broken down into the following series of steps: 
i. Preparation of the artwork.

ii. Photography of the artwork with a suitable camera to make a photographically reduced working image of the desired pattern.

iii. Exposure of a photoresist-coated surface, using the photographically reduced negative.

iv. Development of the exposed photoresist in the proper developer.

v. Etching of the surface.

Kodak photosensitive resists (KPR) are liquid formulations of resins. When applied to a material surface and allowed to dry, they become sensitive to relatively short exposures of ultraviolet radiation. When exposed to $u 1$ traviolet radiation, through a photographically reduced transparency, the resist "cross-links" or polymerizes in the areas that are struck by ultraviolet radiation (Fig. 4). The image formed by the ultraviolet radiation and defined by the clear areas of the transparency is insoluble in the developing bath. The opaque areas of the transparency act as a mask and allow those portions that have received no exposure to be dissolved in the developer. The soluble portions wash away and leave a tough, chemically resistant image in minute relief on the surface. This image acts as a clearly defined mask for etching.

i. Artwork - In order to produce a part by the photofabrication process a master or working transparency of the desired pattern will be needed. This is obtained by first drafting the pattern, usually somewhat larger than its final size, and then photographically reducing this master artwork to the required size. In this way, drafting errors are reduced, and the pattern on the transparency has greater accuracy. 
The pattern of reinforcements was drawn by hand on drafting paper twice the actual size of the finished grid.

ii. Photography - One of the most important steps in photofabrication is photography of the artwork, since the quality of the finished part is directly dependent on the quality of the transparency used to produce the part.

A transparency used as a working master for photofabrication must possess two attributes: sharpness and density. Additionally, the clear areas of the transparency must offer a minimum density in order to effect a complete photoresist exposure.

Maximum sharpness on a transparency is needed because of the extremely high resolution capabilities of KPR. The transparency must also have sufficient high density in opaque areas to prevent exposure of the photoresist in the areas that are to be developed away. A photoresist image that has been exposed to a transparency low in density will be "fogged". This means that there is not onily exposed resist in the pattern area but also partially-exposed resist on the surrounding portions of the surface. Processing of an image in such condition is very difficult and yields unsatisfactory parts.

As mentioned before, photographic reduction of the artwork is used. Thus, the camera which is used must have good characteristics for photographic reduction. Furthermore, the film must also have high contrast characteristics. To satisfy these requirements, a telephoto lens on a bellows-type camera and Kodak Ortho Film, Type 3, were used for this work. The camera back, lens board, and copy board were, of course, set up parallel to one another. 
iii. Coating and Exposure of Photoresist - In order to perform satisfactorily, Kodak photosensitive resists must be applied to thoroughly clean surfaces. Resist failures, when they occur, are usually traceable to poor or inadequate cleaning techniques.

Therefore, the surface of the brass shim used was cleaned with emery paper of grit 600 and acetone. Then it was washed in running water and was oven dried. After this preparation, KPR was applied to the surface.

Several methods of applying photoresist are possible. These include spraying, whirling, dipping, flowing and roller coating. All of these systems have advantages and disadvantages, and there are specific areas in which each functions best. In this investigation, the whirling method, described below, was used.

There are two kinds of whirler coating methods: low-speed (about $75 \mathrm{rpm}$ ) and high-speed (from $200 \sim 700 \mathrm{rpm}$ )。

A low-speed whirler coating of full strength KPR without forced drying, will yield a coating of average thickness that is capable of good resolution and chemical resistance.

A high-speed whirler coating will give a very thin resist coating that is capable of maximum resolution. Coating thicknesses obtained by this method are excellent from a resolution standpoint and will produce extremely fine detail. Because these coating thicknesses are generally in the micron range, a particular coating thickness or a particular resist dilution is determined empirically. 
The normal procedure with whirling devices is to place a flowcoated plate on the whirler and turn the equipment on. Applying the coating while the plate is whirling should be avoided as incomplete coverage will usually result.

In this research, the photoresist (10 parts resist, $2 \approx 3$ parts KOR Thinner) was applied to the surface of the brass shim with cheesecloth and then a high speed whirler was used for a few seconds. After this, the photoresist coated brass shim was dried at room temperature for about 20 minutes and then the other surface of the brass shim was coated in the same way.

Baking the photoresist layer prior to exposure is often helpful for a particular photofabrication process. The purpose of the prebake is to remove any residual photoresist solvent that has not been eliminated by air drying. Therefore, the photoresist coated brass shim was prebaked in an oven for 10 minutes at $80^{\circ} \mathrm{C}$.

Kodak photoresists are sensitive to a particular range of the light spectrum. The peak spectral sensitivities of these resists are in the near ultraviolet, between 230 and 550 millimicrons.

Typical light sources for KPR include carbon-arc lamps, highpressure mercury-vapor lamps, and so on. In fact, any high-energy light source that is rich in the near-ultraviolet region of the spectrum can be used. Here two $275 \mathrm{w}$ sunlamps, shown in Fig. 5, were used as the light source.

Optimum exposure levels giving the highest resolution were established in the following manner. The resist-coated plate was illuminated 
for various periods while exposed parts of the plate were covered with an opaque mask. The plate was processed and examined to determine the acceptable exposure times.

With two sunlamps as the light source, the optimum exposure time was found to be between 4 and 9 minutes. This wide range of exposure times depended on the freshness of the photoresist and the conditions of the transparency.

iv. Development of Exposed Plates - Exposed plates were developed in a tray. Care must be exercised with double-sided work, as there is a danger that one side of the image may be scored by the bottom of the tray. To avoid such damage, the exposed, coated brass shims were developed with very gentle agitation. Even so, small spots of damage appeared on some shims. When small damage occurred on the back surface it was covered with an adhesive tape before the etching.

After completing the development, the surface was washed in running water, dyed with a Kodak Photo Resist Dye for 30 seconds, and was washed again. Finally, plates were postbaked for 10 minutes at $120^{\circ} \mathrm{C}$.

v. Etching - The basic problem of etching is that reaction products (as a result of the chemical dissolution of metal) are not carried away from the surface of the brass rapidly. These products then concentrate on the surface and often retard the action of the etching bath. As these products build up, the etchant seeks more metal to dissolve, and eventaally starts to etch the metal under the resist as shown in Fig. 6. This, of course, causes a poor etch factor which is defined as the depth of etch divided by the amount of sideward growth observed 
when a line is etched. It is calculated for one side of a line only.

A way around the problems of etching is to provide agitation in the etching solution. This helps to remove reaction products, and to improve etch factors.

Agitation may be provided by either stirring the etching bath, bubbling air through the solution, or by spraying the etchant on the surface. In this experiment the brass shims were etched with a ferric chloride solution in a hand agitated glass tray. With this technique the reaction products cannot be removed well from the surface.

In order to solve this problem, the surface of the brass shim was washed several times with running water during the etching procedure. This provided a fresh surface for the etchant to act upon and reduce etching time and severe undercutting of the image. The frequency of surface washing depended on the thickness of brass shim and the required accuracy of reinforcement.

In addition, to reduce etching time, the etchant was heated to about $55^{\circ} \mathrm{C}$.

Etching time was not constant, since it depends on the freshness of the solution, agitation and temperature. For the 0.005 inch thick brass shim, the exching time was about $60 \sim 90$ minutes including the time of about 15 surface washings.

\subsection{Specimen Geonetry and Photoelastic Test Procedure}

Reinforcements following the pattern of the stress trajectories for an infinite plate with a hole under an uniaxial tensile load were 
constructed as described in sections 3.1 and 3.2. Composite specimens were then made by sandwiching the brass shim reinforcement between two birefringent plates of epoxy resin (Photolastic PS-2C). The thickness of the brass shim, i.e., the thickness of reinforcement, was $0.005 \mathrm{in}$. while the thickness for PS-2C was $0.040 \mathrm{in}$. each.

0.005 in. brass shim is relatively thick for the photofabrication method, and hence it was difficult to obtain a good etch factor. Therefore, the line width of the reinforcements was not exactly constant. These average widths of 7 ines are shown in Table 1 in Chapter 4.

Epoxy resin PMC-1 was used as the bonding cement. After gluing a reinforcement and two epoxy resin plates together, the specimen was machined and a hole was milled at its center. Though the stress trajectories were computed for an infinite plate with 0.5 in. diameter hole, the actual hole size was $0.436 \mathrm{in}$. in order to leave some photoelastic material inside the reinforcement. The specimen geometries are shown in Figs. 7 and 8. After finishing the examinations of the specimens with 0.436 in. diameter holes, the hole size was enlarged to 0.535 in., in the specimens $A$ and $B$.

In specimens $A$ and $C$ (Figs. 7 and 8 ) the reinforcement follows lines corresponding to the stress trajectories for an infinite plate with $0.436 \mathrm{in}$. hole. Specimens $B$ and $D$ have straight line reinforce-

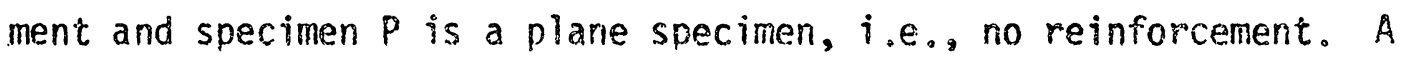
prime indicates the specimens with 0.535 in. diameter holes.

The specimens were then placed in the field of a circularly polarized, point light source, polariscope. The load frame is shown in Fig. 9. The applied load was determined from the displacement of 
the specimen, which was measured by a dial gage.

The light source was a white, mercury vapor lamp using an appropriate green filter to produce monochromatic light. The resulting fringe patterns were photographed using both light and dark field, and the Tardy method to determine the intermediate fringes between fringes of light and dark field and to determine the fringes at the edges. In order to ascertain the cupic point of each specimen, $0^{\circ}$ isoclinic fringe patterns were also photographed.

Fringe patterns were photographed with a telephoto lens on a bellowstype camera using Kodak Contrast Process Ortho $4 " \times 5^{\prime \prime}$ film sheets. Negatives were printed on a high contrast paper. The fringe pattern was enlarged to approximately four times the actual size of the specimen. The use of both high contrast film and paper aided significantly in reducing the thickness of the fringes, thus making distance measurements of fringe center lines from the edge of the hole more accurate. Sample photographs are shown in Figs. 10 to 13 .

It is well known that the stress optic relationship is given by

$$
\sigma_{1}-\sigma_{2}=\frac{f n}{t}
$$

where $\sigma_{1}$ and $\sigma_{2}$ are principal stresses, $f$ is the materiai fringe value, $n$ is the fringe order, and $t$ is the thickness of the specimen. Since $\sigma_{2}$ equals zero at the edge of the hole, Eq. $(3-17)$ can be simplified to

$$
\sigma_{1}=\frac{f n}{t} .
$$

The stresses at the edge of the hole for each specimen was calculated 
using Eq. (3-18). From which then the stress concentration factors $K_{t}$ were determined using Eq. $(1-2)$.

The material fringe values for PS-2C and for the reinforced materials were determined by the calibration method [22], [23] with tensile specimens. These values are shown in Table 1 in Chanter 4. 


\section{RESULTS AND DISCUSSION}

The differences of principal stresses, $\sigma_{1}-\sigma_{2}$, on the transverse axis of symmetry through a central circular hole are measured as mentioned above and are plotted in figures 14 to 20 . The principal stresses, $\sigma_{1}$ and $\sigma_{2}$, are also determined by a slope equilibrium (rapid) method [24], which is based on the Lame-Maxwell equations of equilibrium and Mesnager's theorem, and are illustrated in the same Figures 14 to 20. The stress concentration factors $k_{t}$ and all other pertinent data are recorded in Table 1 .

Figures 14 to 20 show no significant differences between the shapes of curves for the different specimens.

On the other hand, considering specimens with the same hole diameter (0.436 in.), that is, specimens $A, B, C, D$ and $P$, stress concentration factors for the reinforced specimens are found to be smaller than that of the plane specimen $P$. Specimen $C$ (analogue) had a minimum value of $K_{t}$ with a $19 \%$ reduction of the stress concentration factor compared to the plane specimen $P$. Specimens $A$ and $D$ showed a $12 \%$ reduction. On the other hand, specimen $B$ which had the least amount of straight reinforcement exhibited only $5 \%$ reduction of the stress concentration factor.

As shown in Table 1 , volume fractions were $0.022,0.016,0.023$ and 0.020 for specimens $A, B, C$ and 0 , respectively. While these volume fractions are small in comparison with those of structurally useful composite materials, a $19 \%$ reduction in the stress concentration factor 
for specimen $C_{8}$ with analogue reinforcement, shows a significant alleviation of the stress concentration around the hole.

Though the volume fraction of the reinforcement in specimen $A$ (analogue) is $37 \%$ larger than that of specimen $B$ (straight), the stress concentration factor is reduced by only $8 \%$ in comparison with specimen $B$. On the other hand, the value of $K_{t}$ for specimen $C$ (analogue) with $15 \%$ larger volume fraction was reduced $8.5 \%$ with respect to the specimen 0 (straight).

For the two specimens with analogue reinforcement, $4.5 \%$ increase of the volume fraction caused $8 \%$ reduction in the stress concentration factor ( $A$ vs. $C$ ). In the case of the two straight reinforcements, $25 \%$ increase of the volume fraction caused $8 \%$ reduction in the stress concentration factor ( $B$ vs. D). That is, the increases of $4.5 \%$ and $2.5 \%$, in volume fraction, introduced the same reduction, $8 \%$, in the stress concentration factor. In order to explain this difference, the distance from the edge of the hole to the inner edge of the nearest reinforcing line will be examined.

The distances from the edge of the hole to the inner edge of the nearest reinforcing line are shown in Table 1. The differences betweer specimens are appreciable. The value of $K_{t}$ of specimen $C$ was reduced $8 \%$ with $34 \%$ decrease of the distance from the edge of the hole to the nearest reinforcing line and $4.5 \%$ increase of the volume fraction (C vs. A). On the other hand, the value of $K_{t}$ of specimen $D$ was decreased $8 \%$ with $2 \%$ increase of the distance from the edge of the hole to the nearest reinforcing line and $25 \%$ increase of the volume fraction (D vs, B). 
From the above discussion, it may be deduced that the larger volume fraction gives rise to a smaller value of the stress concentration factor. It may also be concluded that the shorter the distance from the edge of the hole to the nearest reinforcing line the smaller the value of the siress concentration factor.

The distance from the edge of the hole to the nearest reinforcing line for specimen A (analogue) was 3.2 times larger than for specimen $B$ (straight), and in specimen C, 2.1 times larger than in specimen $D$. Though the analogue reinforced plates have larger distances from the edge of the hole to the nearest reinforcing line, the value of $K_{t}$ for specimens $A$ and $C$ is $8 \%$ and $8.5 \%$ smaller than for specimens $B$ and $D$, respectively. Therefore, if these distances and the volume fractions were the same for each specimen, the stress concentration factors for the specimens with analogue reinforcement would be reduced much more than for plates with straight reinforcement.

Specimens $A^{\prime}$ and $B^{\prime}$ with 0.535 in. diameter holes were examined to determine the effect of the distance from the edge of the hole to the nearest reinforcing line. The values of $K_{t}$ for specimens $A^{\prime}$ and $B^{\prime}$ were 3.08 and 3.51 respectively as shown in Table 1 , and the value of $K_{t}$ for specimen $B^{\prime}$ is $14 \%$ greater than that of the specimen $A^{\prime}$. These values increased more rapidly than that of the theoretical solution for an infinite, honogeneous, isotropic piate (see Fig. 21). Furthermore, the stress concentration factor of specimen B' was larger than the theoretical value. 
As mentioned in the previous chapter, the holes in specimens $A$ and $B$ were enlarged to 0.535 in. diameter $\left(A^{\prime}, B^{\circ}\right)$ after they were tested with the original $0.436 \mathrm{in}$. diameter hole. Residual stresses which could not be ignored were found around the holes. The steep increase, therefore, may be due to the influence of these residual stresses.

At the same time, the value of $K_{t}$ for specimen $B^{\prime}$ increased more rapidly than for specimen $A^{\prime}$. As shown in Table 1 , the distances from the edge of the hole to the nearest reinforcing line are 0.0114 and 0.0883 in. respectively for specimens $A^{\prime}$ and $B^{\prime}$. The distance for specimen $B^{\prime}$ is 7.75 times larger than for specimen $A^{\prime}$. Therefore, the steeper increase of $K_{t}$ for $B^{\prime}$ may be contributed to the large distance between the edge of the hole and the nearest reinforcing ine in addition to the influence of the residual stresses,

A comparison of these stress concentration factors with the experimental results of Daniel and Rowlands is shown in Figure 21. In this figure, the present experimental results are denoted by small circles and curve (1) represents the results for $[90 / 0 / 90 / 0]_{S} 7$-ply glass-epoxy laminates as determined by Daniel and Rowlands. The numerical value of the stress concentration factor for an isotropic material as a function of hole size is illustrated by the solid line [2]. The theoretical stress concentration factor for an anisotropic material, determined by Daniel and Rowlands and denoted by an asterisk, was computed usina the following expression: 


$$
k_{t}=1+\sqrt{2\left(\sqrt{\frac{E_{L}}{E_{T}}-\nu_{L T}}\right)+\frac{E_{L}}{G_{L T}}}
$$

where $E_{L}, E_{T}=$ elastic moduli in the iongitudinal and transverse directions respectively

$v_{L T}=$ Poisson's ratio

$G_{L T}=$ shear modulus, related to the values of elastic moduli and Poisson's ratio by the relation

$$
\frac{1}{G_{L T}}=\frac{4}{E_{45}}-\frac{1-2 v_{L T}}{E_{L}}-\frac{1}{E_{T}}
$$

According to curve 1 , the stress concentration factor for a 0.436 in. hole is about 4.0. This value is nuite large in comparison with the theoretical value of 3.19 for an isotropic plate. On the other hand, every experimental value measured in the present investigation was less than the theoretical value for an isotropic plate (with the exception of $\left.B^{\prime}\right)$. The specimens of Daniel and Rowlands were $[90 / 0 / 90 / 0]$ s glass-epoxy composites with a volume fraction of glass-fibers $v_{f}=0.45$, while the volume fractions in the present investigation are about 0.02 .

As mentioned in Chapter 2, Hyman reported tensile test results on fiber reinforced plates with circular holes. In his investigation, he found that the drilled hole had more of a weakening effect on bidirectional composite plates than it did on unidirectional plates (Group IB vs. Group 1C, see Fig. 3).

Therefore, even if the differences in reinforcements are considered, it is interesting to note these large differences in stress concen- 
tration factors between the Daniel and Rowlands' results and the present resuits together with Hyman's tests.

As mentioned in Chapter 2, Suzuki [13] measured the stress concentration factors in an infinite, aluminum plate with a hole reinforced with various materials. His reinforcing rings are shown in Fig. $2(b)$. The comparison with one of his results for the case of $R_{1} / R_{2}=20 / 23$ is shown in Fig. 22. The curves (1), (2), (3) and (4) are the results for the case of aluminum, brass, copper and mild steel reinforcing rings, respectively. The present results are represented by small circles. The stress concentration factor of specimen $C$ coincides with the case of $h_{1} / h_{2}=1.5$ for a mild steel reinforcing ring. For a reinforcing ring consisting of the same marerial as the plate, i.e., aluminum, the value of $h_{1} / h_{2}$ is about 2. If it is assumed that the thickness of the reinforcement in specimen $C$ is equivalent to the thickness of a reinforcing ring, then the value of $h_{1} / h_{2}$ (tota) thickness of plate) thickness of plastic) for specimen $C$ becomes about 1.055 . For this value of the parameter, the Suzuki's plate would have $k_{t}=3$ while specimen $C$ has a $K_{t}$ value of 2.57 . The situation between Suzuki's specimens and the specimens discussed here are, of course, quite different. But one may expect a large saving in thickness with analogue reinforcement and still obtain same stress concentration factor. 


\section{TABLE}

\begin{tabular}{|c|c|c|c|c|c|c|c|}
\hline & A & $B$ & c & $D$ & P & $A^{0}$ & $B^{\prime}$ \\
\hline Thickness & 0.097 & 0.097 & 0.098 & 0.101 & 0.047 & 0.097 & 0.097 \\
\hline Width & 1.903 & 1.001 & 1.907 & 1.905 & 1.898 & 7.905 & 1.901 \\
\hline Hole Diameter (in.) & 0.436 & 0.436 & 0.436 & 0.436 & 0.436 & 0.535 & 0.535 \\
\hline Applied Load (Bb.) & 240 & 240 & 240 & 240 & 180 & 228 & 228 \\
\hline $\begin{array}{l}\text { Materiai Fringe Value }(f) \\
\text { (psi-in./fringe) }\end{array}$ & 75.2 & 75.2 & 75.2 & 75.2 & 58.7 & 75.2 & 75.2 \\
\hline $\begin{array}{l}\text { Stress Concentration } \\
\text { Factor }\left(k_{t}\right)\end{array}$ & 2.80 & 3.04 & 2.57 & 2.81 & 3.19 & 3.08 & 3.51 \\
\hline $\begin{array}{l}\text { Line Width of } \\
\text { Reinforcement (in.) }\end{array}$ & 0.0255 & 0.0213 & 0.0740 & 0.0145 & $\ldots$ & 0.0244 & 0.0213 \\
\hline Volume Fraction $\left(V_{f}\right)$ & 0.022 & 0.016 & 0.023 & 0.020 & $\cdots$ & 0.022 & 0.016 \\
\hline Distance* (in.) & 0.0537 & 0.0167 & 0.0356 & 0.0170 & -- & 0.0174 & 0.0883 \\
\hline
\end{tabular}

*Distance: Distance from the edge of the hole to the nearest reinforcing line 


\section{CONCLUSIORS RARD RECORMENDATIONS}

In spite of the small volume fraction used, considerable alleviation of the stress concentration factor was obtained with the use of analogue reinforcements. In these specimens, reinforcing lines coincide with the stress trajectories of an isotropic plate. Results were compared with those obtained on specimens containing straight, rectangulargrid type reinforcement. It was aiso observed that larger volume fraction resulted in a smaller stress concentration factor in both types of specimens. That is, the specimen with analoque reinforcement and the largest volume fraction had a smallest stress concentration factor, and the specimen containing straight reinforcement wich the smallest. volume fraction had the largest stress concentration factor. This suggests that analogue reinforcement with volume fractions of practical values will produce reasonable small stress concentration factors.

In closing, the author wishes to make the following recommendations for future experiments in this area.

(1) Tests should be performed with larger volume fractions, since the volume fraction of the reinforcement in the specimens used here was too small.

(2) Experiments should also be performed on laminated composites where the reinforcement is arranged in an analogue pattern around the hole while it has a standard $[90 / 0]_{s}$ configuration elsewhere.

(3) Tests with several values of the ratio of $a / b$ should be performed and should be compared with the well known values for an isotropic plate. 
(4) In this investigation, the diameter of the hole for the calculation of the siress trajectories and the actual hole sizes used in the specimens were different in order to leave some birefringent material inside the reinforcement. To avoid this problem and to obtain more accurate data, a birefringent coating method, or a moire technique may be considered in future experiments. 
REFERENCES

1. Kirsh, G., VDI, yol. 42, 1898. (or Timoshenko and Goodier, "Theory of Elasticity," McGraw-Hill Book Co., 3rd Ed. p. 90).

2. Timosherko, S. and Goodier, J. H., "Theory of Elasticity," McGrawHill Book Co.. 3rd Ed. pp. 90-97.

3. Howland, R. C. J., "On the Stresses in the Neighbourhood of a Circular Mole in a Strip under Tension," Philosophical Transactions of the Royal Society of London, Series A, vol. 229, 1930, pp. 49.86 .

4. Timoshenko, S., "On the Stresses in a Plate with a Circular Hole," Journal of the Franklin Institute, vol. 197, 1942, pp. 505-576.

5. Sezawa, K. and Kubo, K. "Stresses in a Plate with a Flanged Circular Hole," Report of the Reronautical Research Institute, Tokyo Imperial University, Tokyo, Japan, no. 84, September, 1932.

6. Gurney, $G_{0}$, "An Analysis of the Stresses in a Flat Plate with a Reinforced Circular Hole under Edge Forces," British Rep. Meno No. 1834, February, 1938.

7. Beskin, L. "Strengthening of Circular holes in Plates under Edge Loads." Joumal of Applied Mechanics, vol. 11. No. 3, September, 1944. pp. 140.748.

8. Levy, S., Mcpherson, A. E. and Smith, F. C., "Reinforcement of a Small Circular Hole in a Plane Sheet under Tension, Journal of Applied Mechanics, vol. 22, Mo. 2, June, 1955, pp. 249-254.

9. Radok, J.R. M., "Problems of Plane Elasticity for Reinforced Boundaries," Journal of Applied Mechanics, vol. 15, No. 2, June, 1948 , pp. 160-168.

10. Muskhelishvili, 1. I., "Some Basic Problems of the Mathematical Theory of Elasticity," N.V.P. Moordhoff, Gronigen, Holland, 1953.

11. Shimada, H., "Influence of Breadth in Bars with Reinforced Circular Holes under Tension," Experimental Mechanics, July, 1961. pp. $33-39$.

12. Suzuki, S. "Stress Measurements in a Plate Containing a Reinforced Circular Hole Using a Photoelastic Method," Int. J. Mech. Sci., vol. 6, 1964, pp, a73-477. 
13. Suzuki, S., "Stress Peasurements in an Infinite Plate with a Hole Reinforced by Different Materials," Experimental Mechanics, July, $1969, \mathrm{pp} .332-336$.

14. Seika, M. and Ishii, M., "Photuelastic Investigation of the Maximum Stress in a Plate with a Reinforced Circular Ho?e under Uniaxial Tension," Journal of Applied Mechanics, Transactions of the ASME, vol. 31, Series E, no. 4, December, 1964, pp. 701-702.

15. Seika, Mo and Amano, A., "The Maximum Stress in a Wide Plate with a Reintorced Circular Hole under Uniaxial Tension - Effects of a Boss with Fillet," Journal of Apolied Mechanics, Transactions of the ASME, vol. 34, Series E, No. T, March, 1967, pp. 232-233.

16. Daniel, I. M. and Rowlands, R. E., "Determination of Strain Concentration in Composites by Poire Techniques," Journal of Composite Materials, voi. 5, April, 1971, pD. 250-254.

17. Gerard, G., "Some Structural Design Aspects of Filamentary Composites," in "The Potentials of Composite Structures in the Design of Aircraft." AGARD Advisory Group for Aerospace Research and Development. Advi sory Report 10, Part I, 1967, po. 1-28.

18. Hyman, B. I., De Turk, A., Diaz, R. and DiGiovanni, G., "Exploratory Tests on Fibermeinforced Plates with Circular Holes under Tension," AIAA Journai, vo1. 7, No. 9, Sentember, 1969, pp. 18201821.

19. Lackman, L.M. and Ault, R. M., "Mollifying Stress Field by Using Filamentary Composite Materials," 12th National SAMPE Symoosium, D-3.

20. "An Introduction to Photofabrication Using KOOAK Photosensitive Resises," KODAK Publication: No. P-79, 1970.

21. "Chemical Milling with KODAK Photosensitive Resists," KOOAK Publication: No. P-131, 1968.

22. Dally, J. W. and Riloy, W. F., "Experimental Stress Aralysis," McGrav-Hil Book Co. 1965.

23. Hetenyi, M. "Hendbook of Experimental Stress Analysis," John Wiley and Sons, Inc., New York, 1960.

24. Frocht, M.M., "Photoelasticity," vol. 1, John Wiley and Sons, Inc., New York, 1965. 
25. Lakhitskin, S. G. "Theory of Elasticity of an Anisotropic Elastic Borly" "trensizted by P. Fern. Hoiden-Day, Inc., San Francisco, 1963.

26. Sayin, G. N., "Stress Concentration Around Holes," Pergamon Press Inc. Hew York, 1967. 


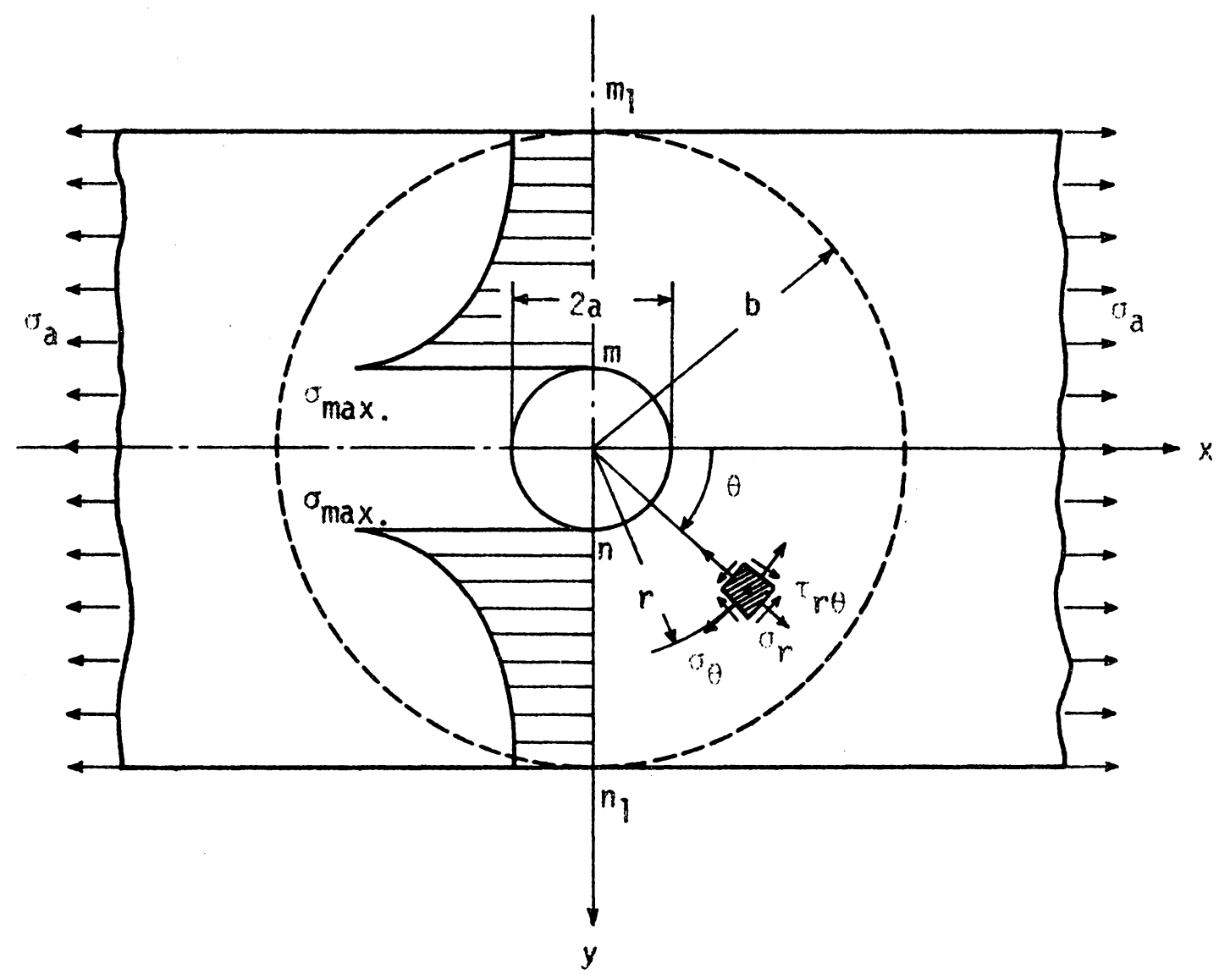

Fig. ". Stresses in Polar Coordinates around a Circuiar Hole for a Bar in Tension 


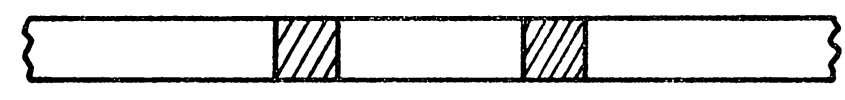

(a)

Shimada, Ref. 11

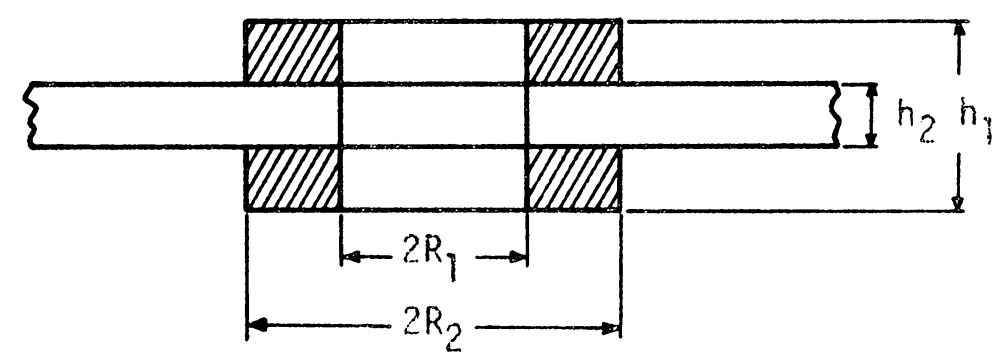

(b)

Suzuki, Refs. 12 and 13

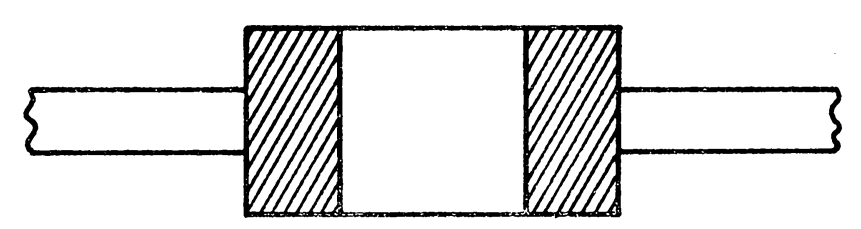

(c)

Seika, Ref. 14

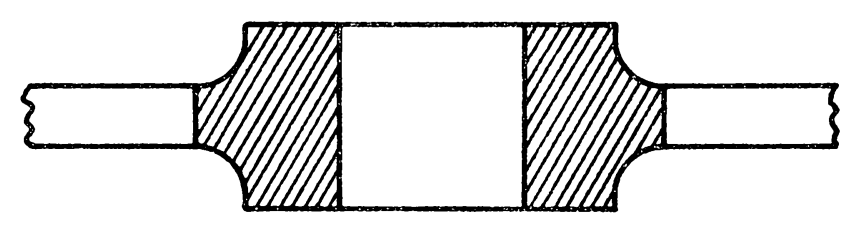

(d)

Seika, Ref. 15

Fig. 2. Various Types of Reinforcing Rings 


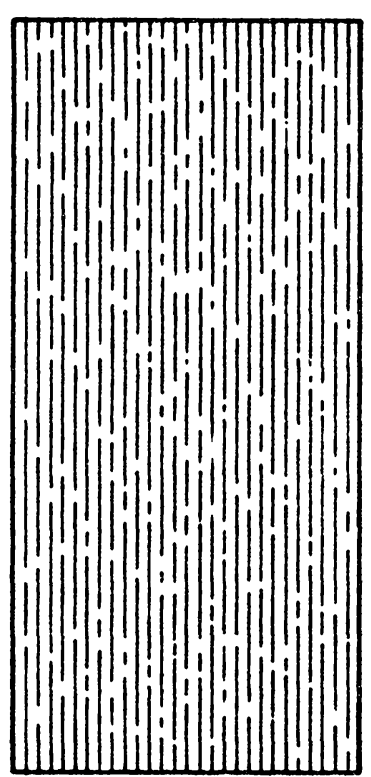

Grour IA

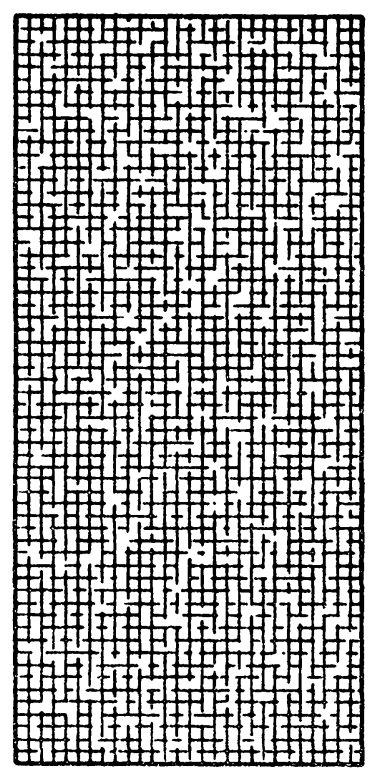

Groun $2 A$

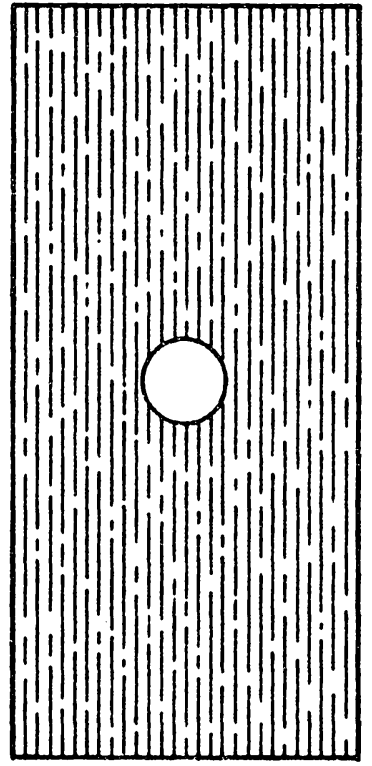

Groun IB

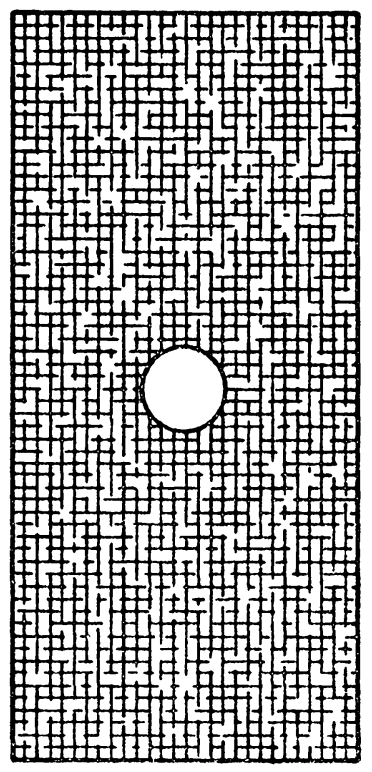

Groun 28

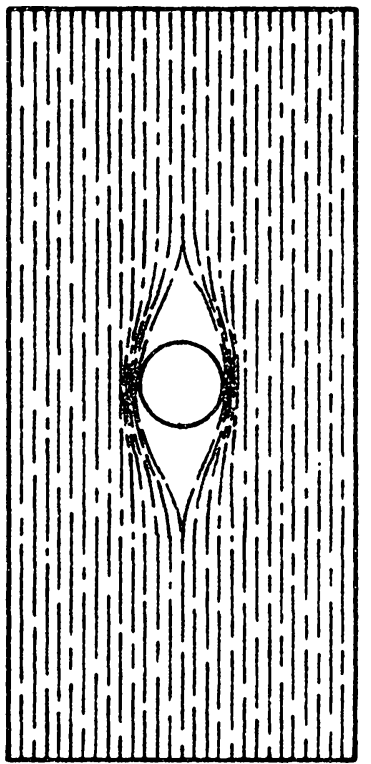

Group ic

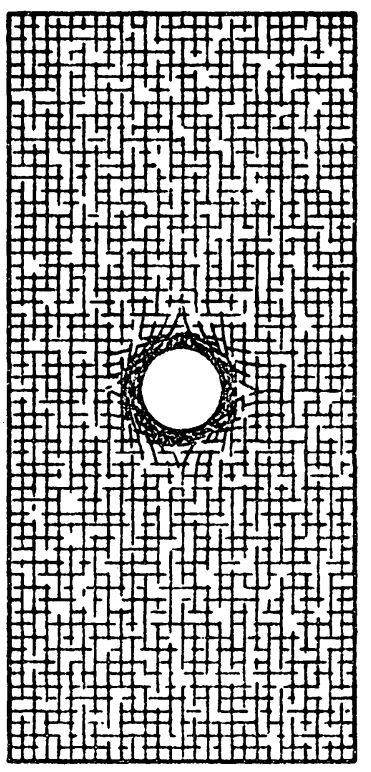

Grour 2C

Fig. 3. Test Specinens of Hyman (Ref, 18) 


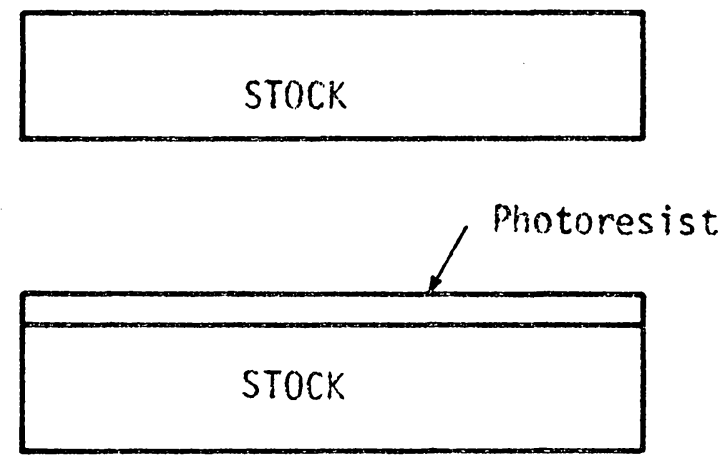

Stock Coated with Photoresist

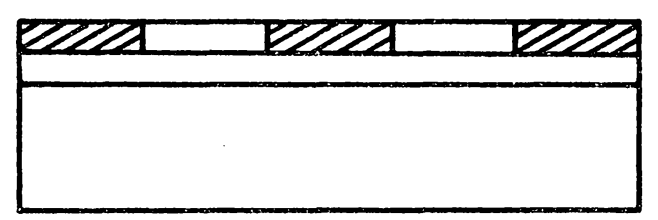

Transparency in plate on the surface

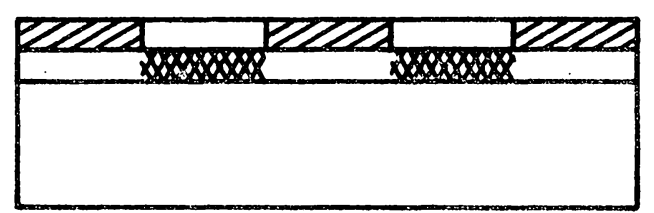

The photoresist receiving exposure

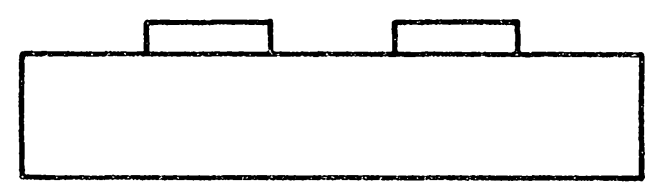

The exposed, developed photoresist layer

Fig. 4. Process of Photofabrication 


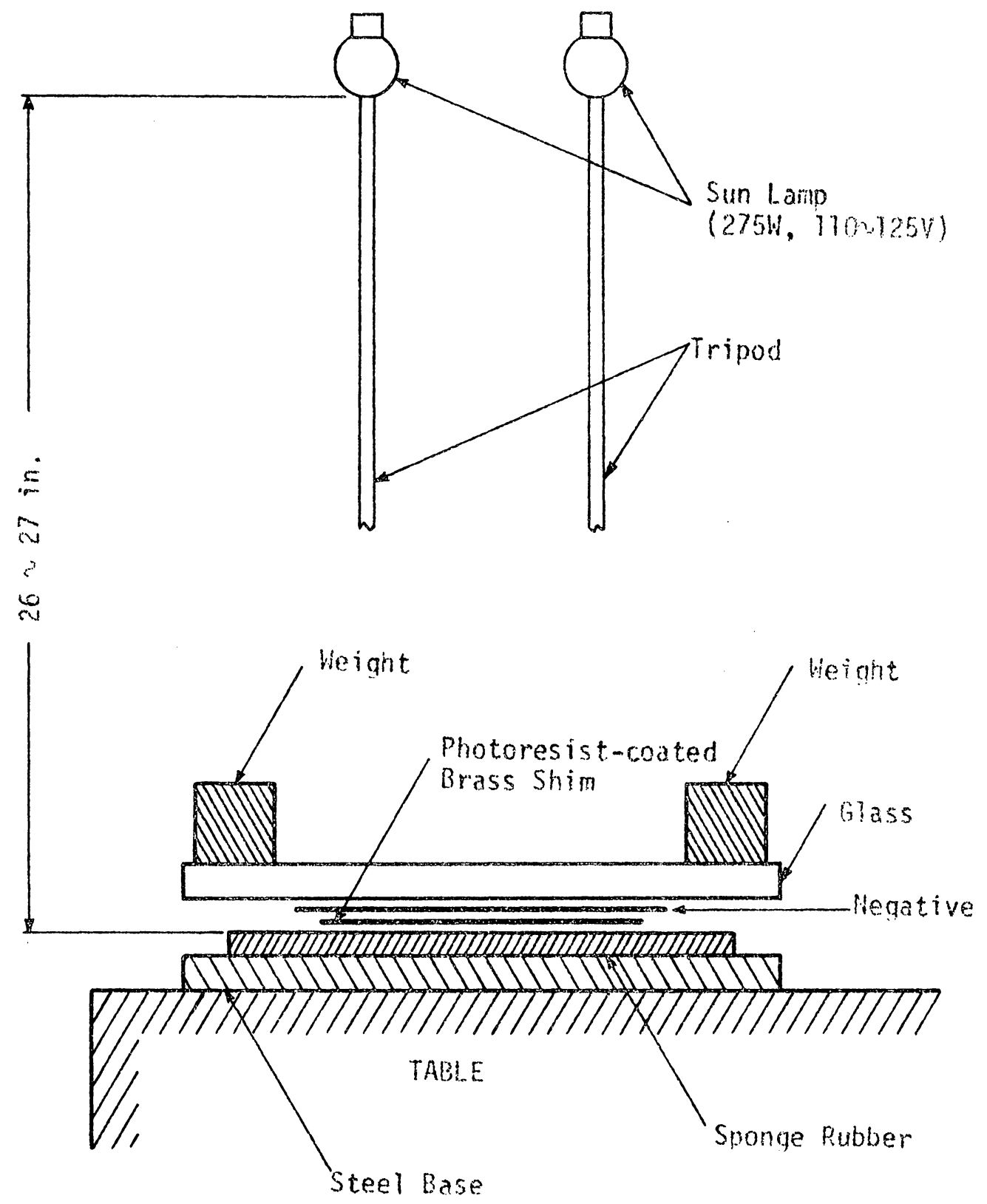

Fia. 5. Apparatus for Exposure in Photofabrication 
Photoresist
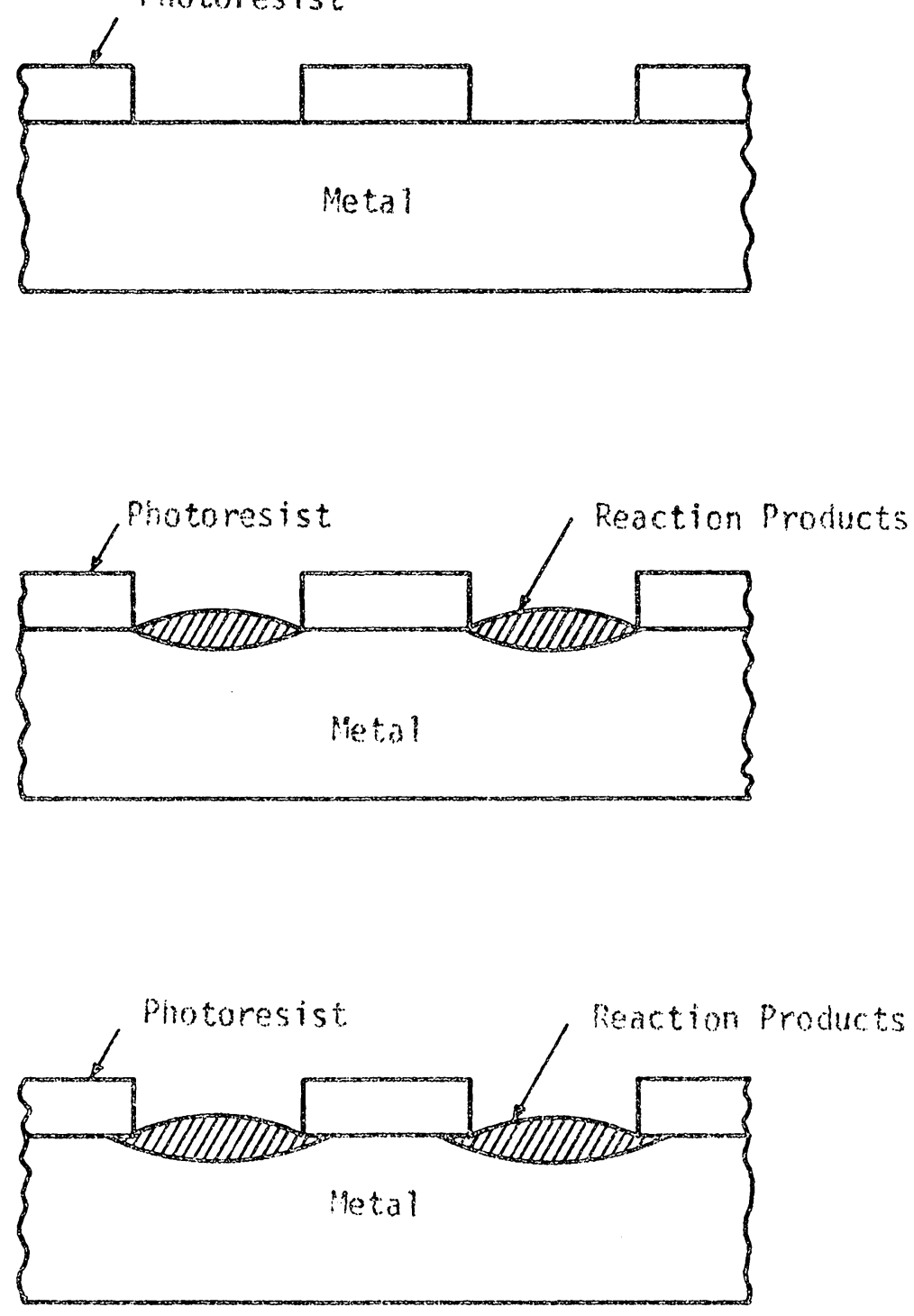

Fig. 6. Reaction Products in Etching Procedure 

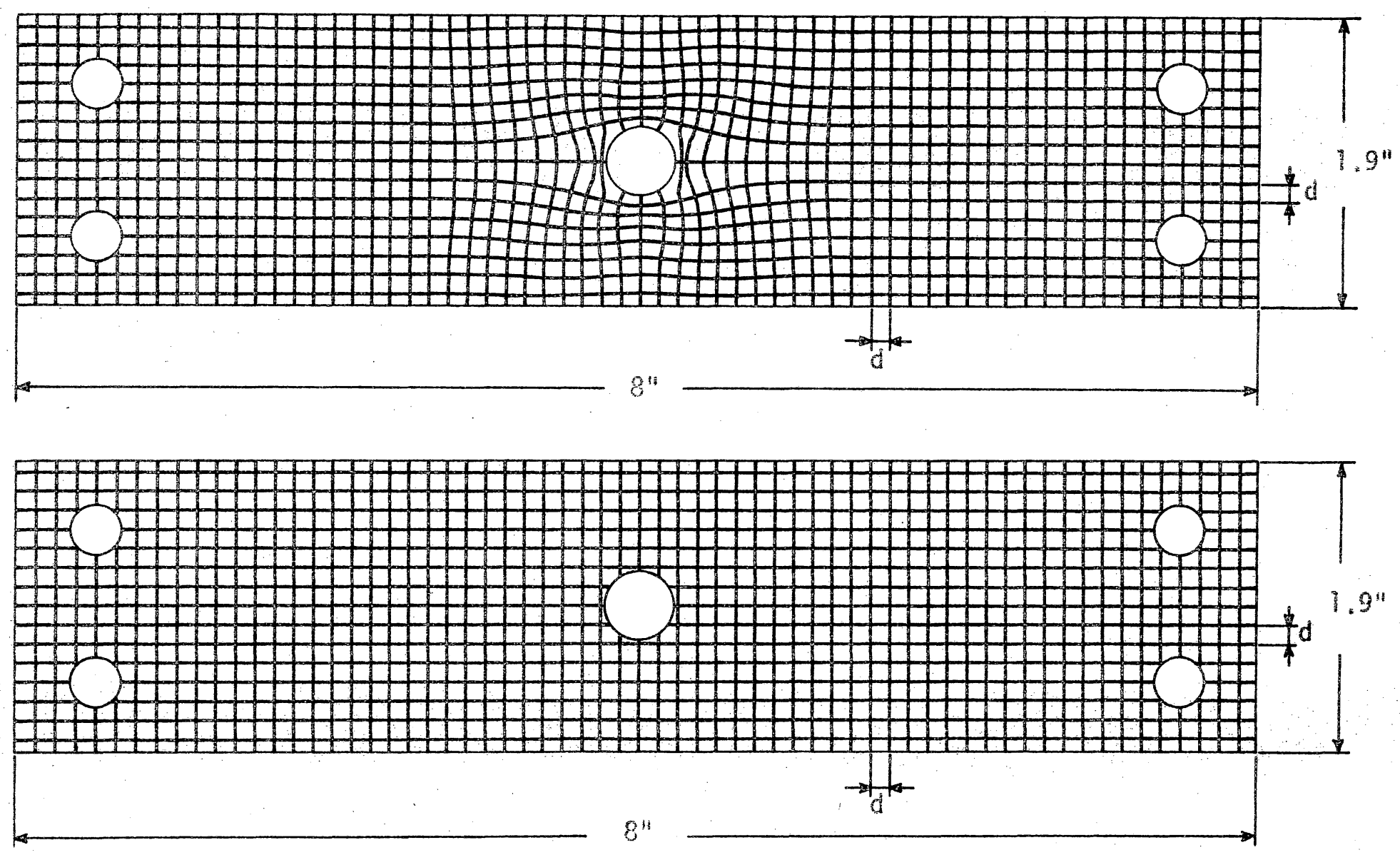

$d=1 / 8 \mathrm{in}$. for Specimens $A$ and $B, d=1 / 16$ in. for specimens $C$ and 0

Fig. 7 , Specimen Geometry 


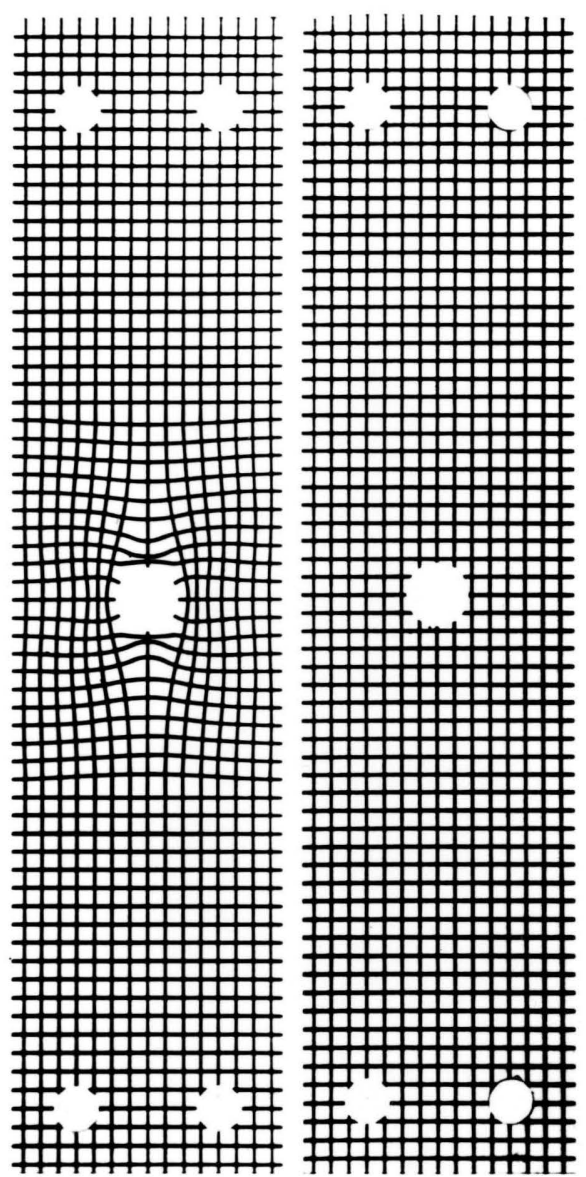

A
B

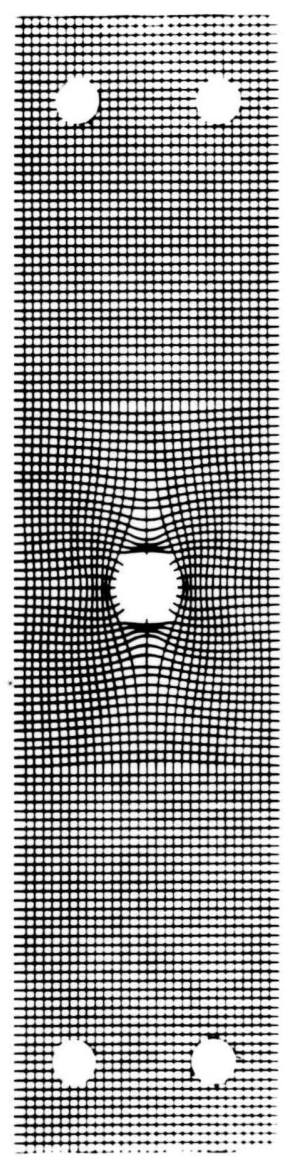

C

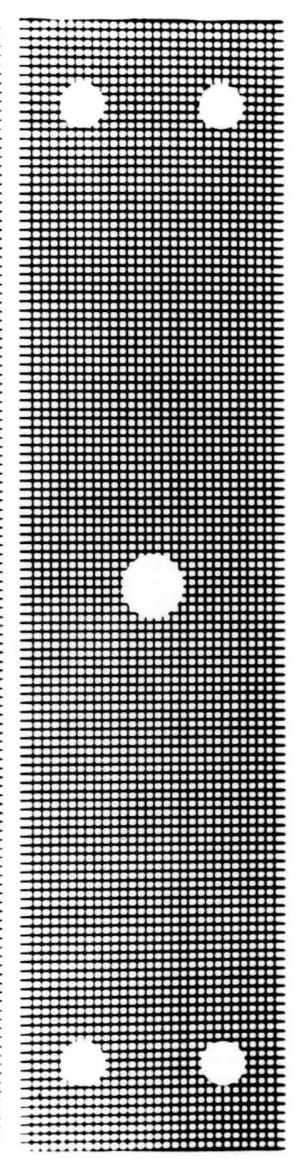

D

Fig. 8. Photograph of Specimens A, B, C and D 


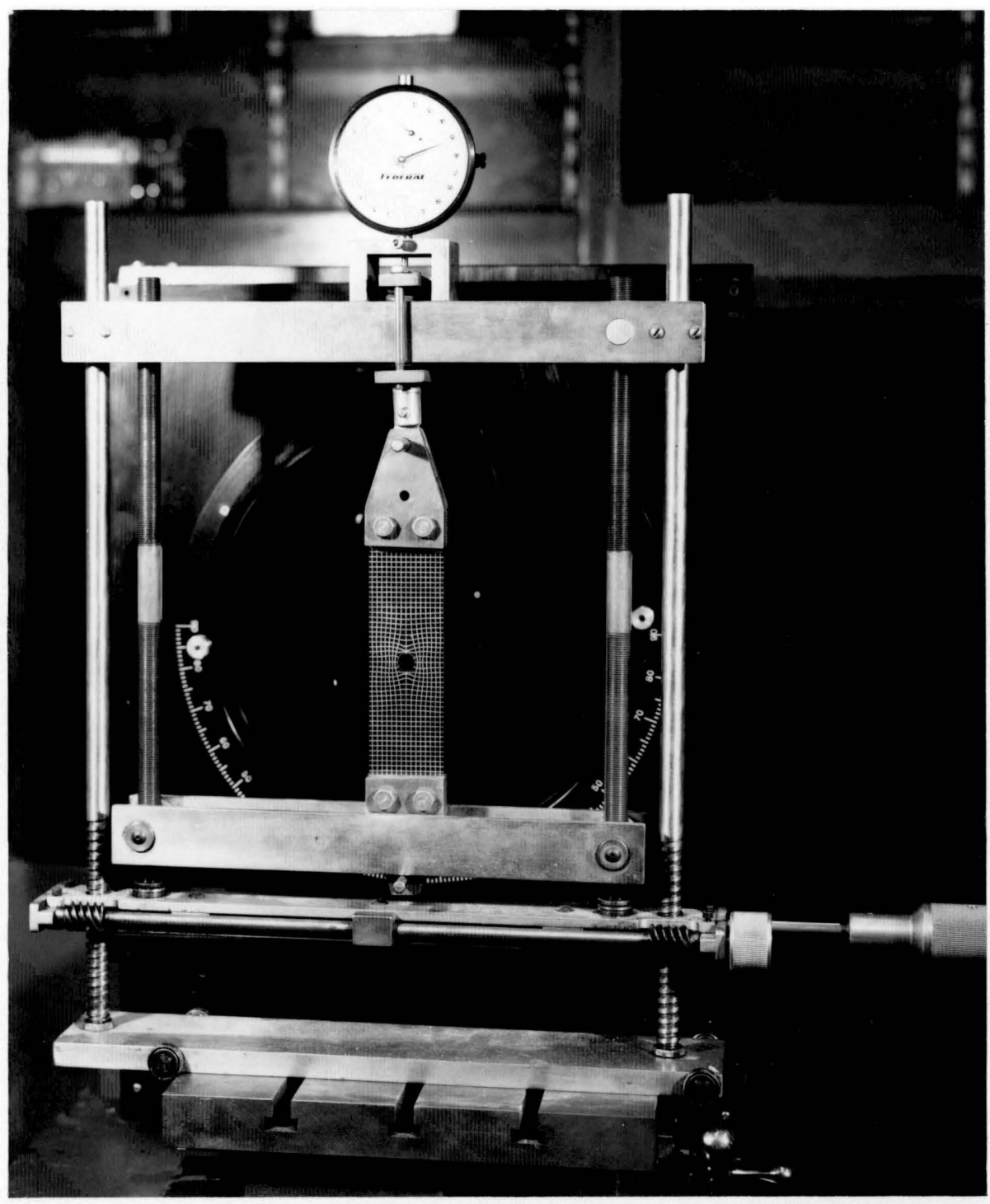

Fig. 9. Loading Device 


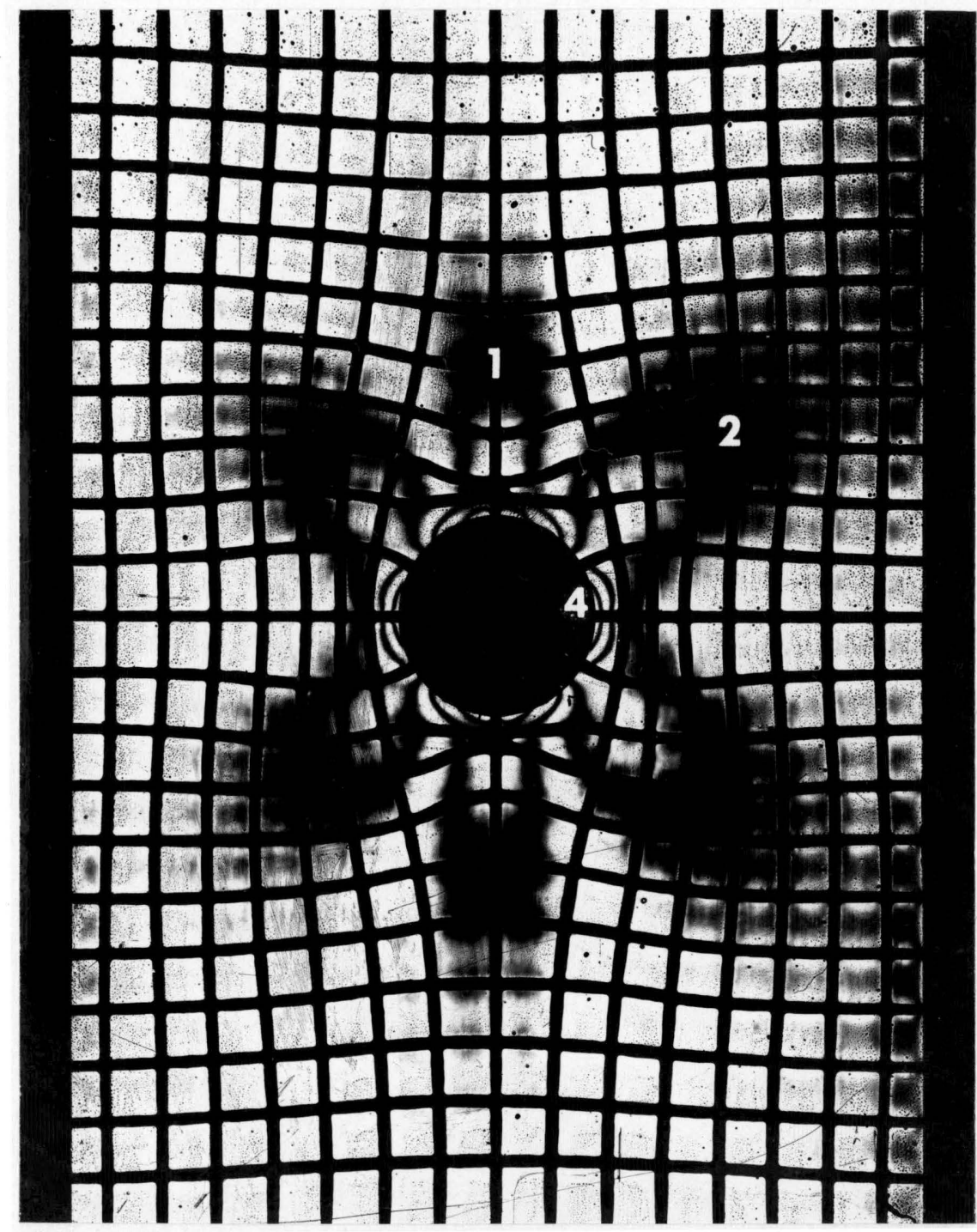

*Dark field

**Numbers denote fringe orders

Fig. 10. Fringe Pattern of Specimen A 


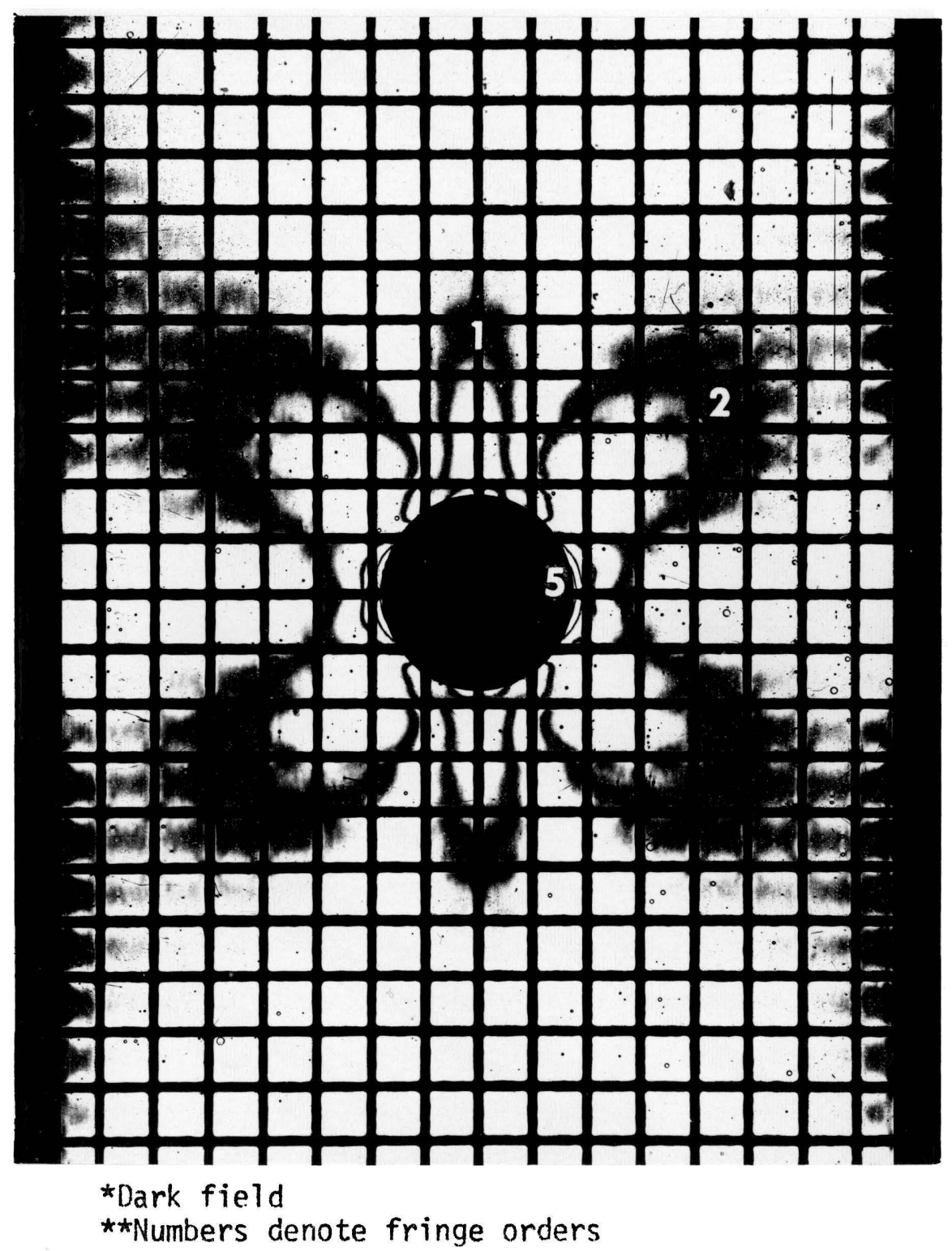

Fig. 11. Fringe Pattern of Specimen B 


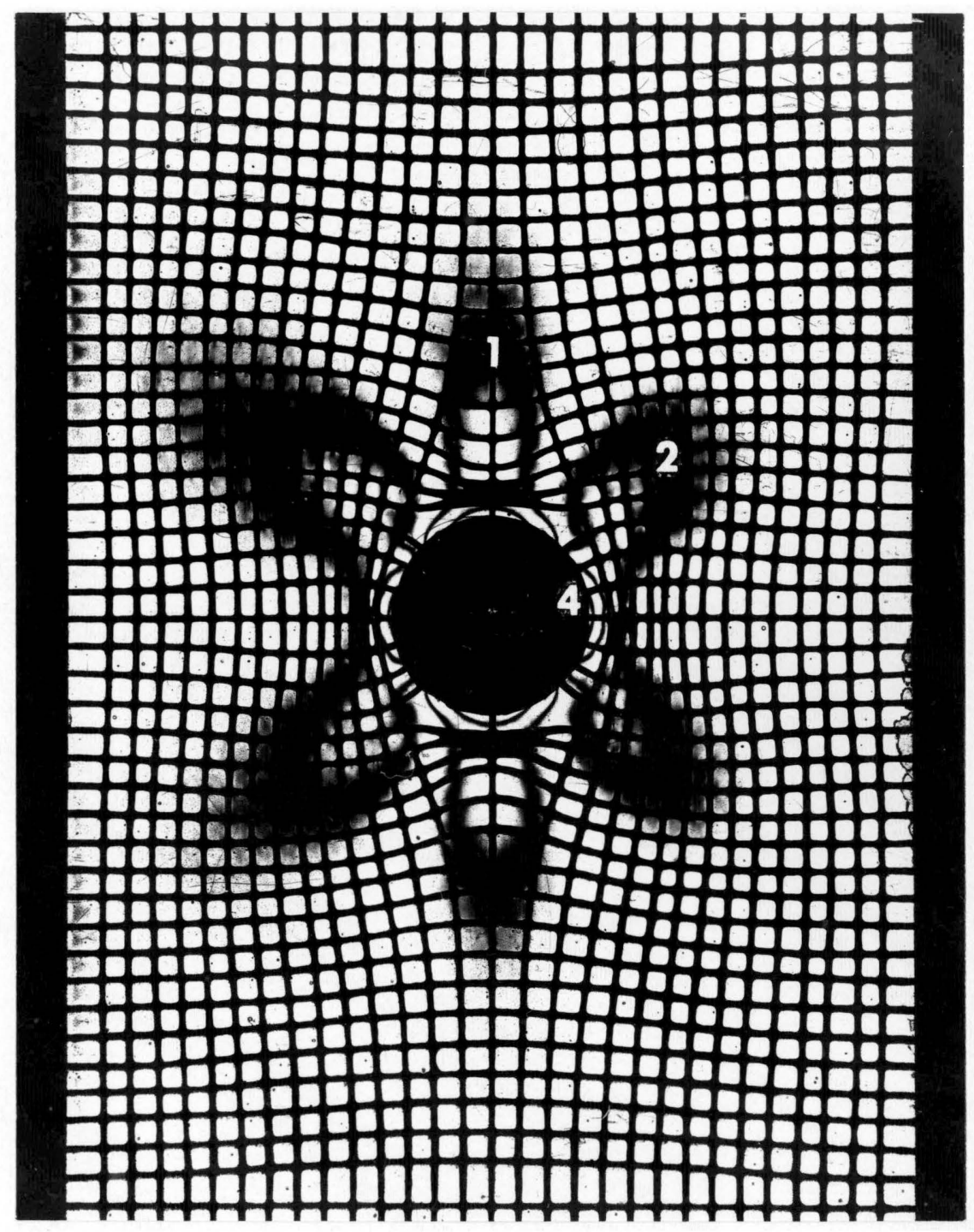

*Dark field

**Numbers denote fringe orders

Fig. 12. Fringe Pattern of Specimen $C$ 


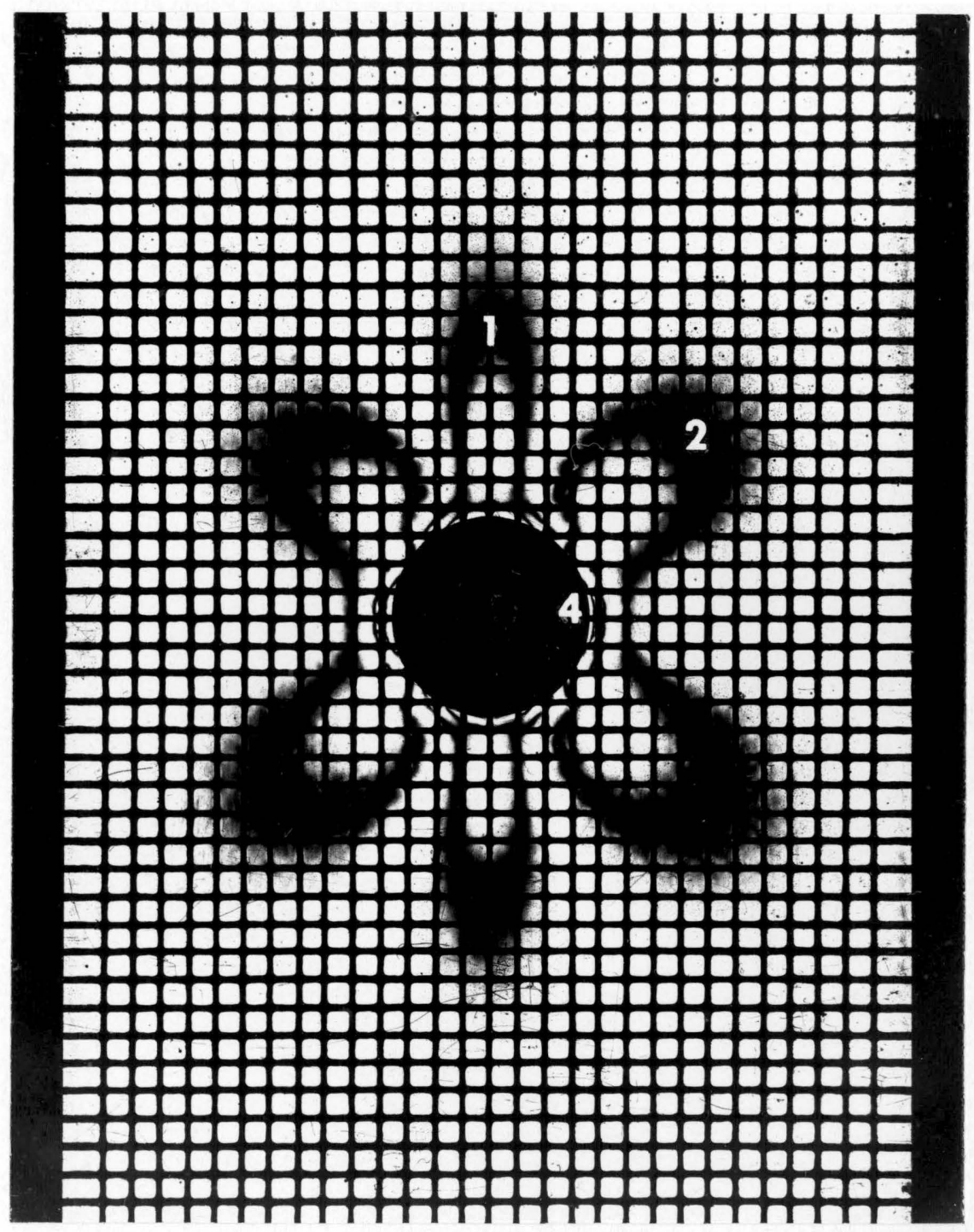

*Dark field

* Numbers denote fringe orders

Fig. 13. Fringe Pattern of Specimen D 


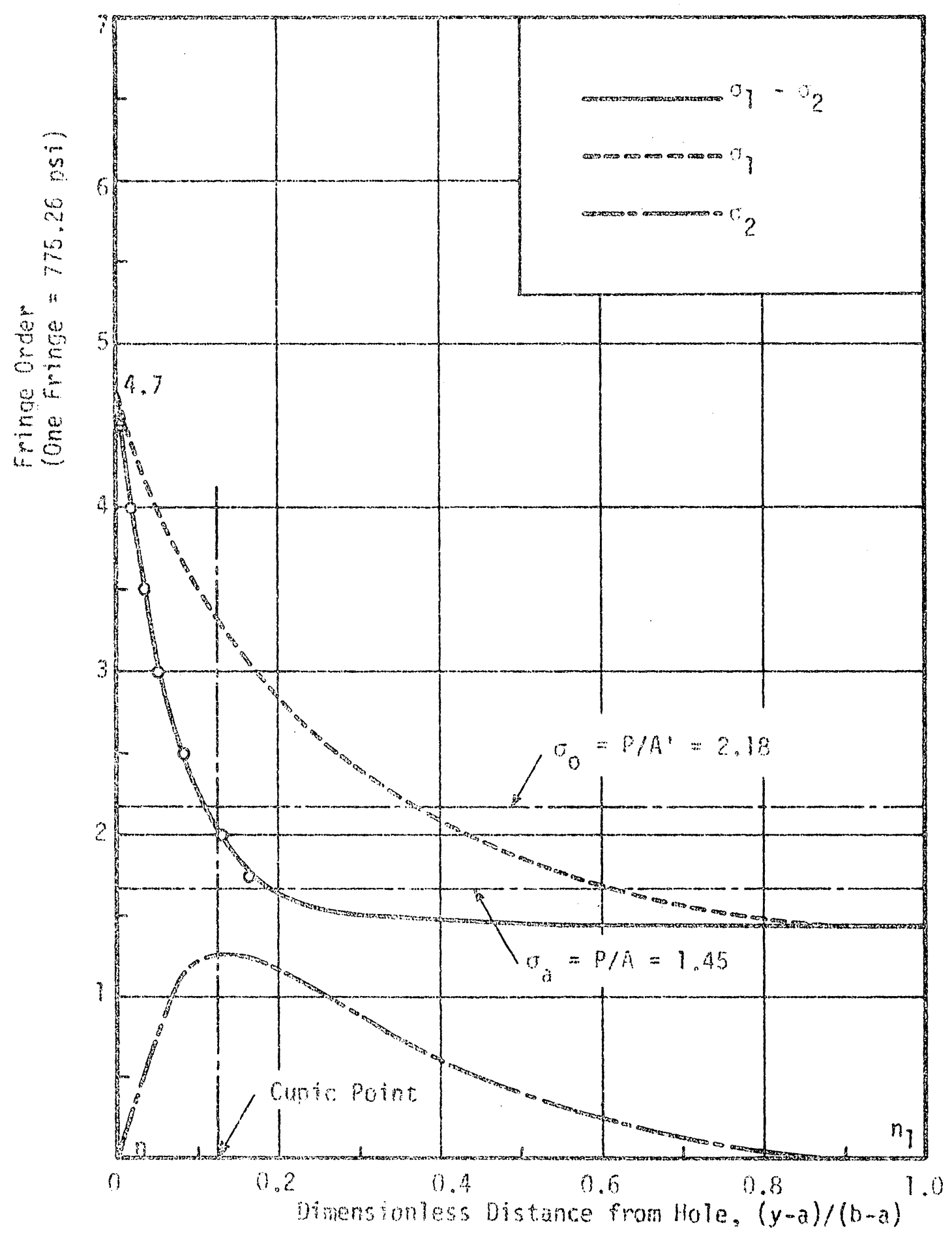

Fig. ia, Stress bisiributions in soecimen $A$ 

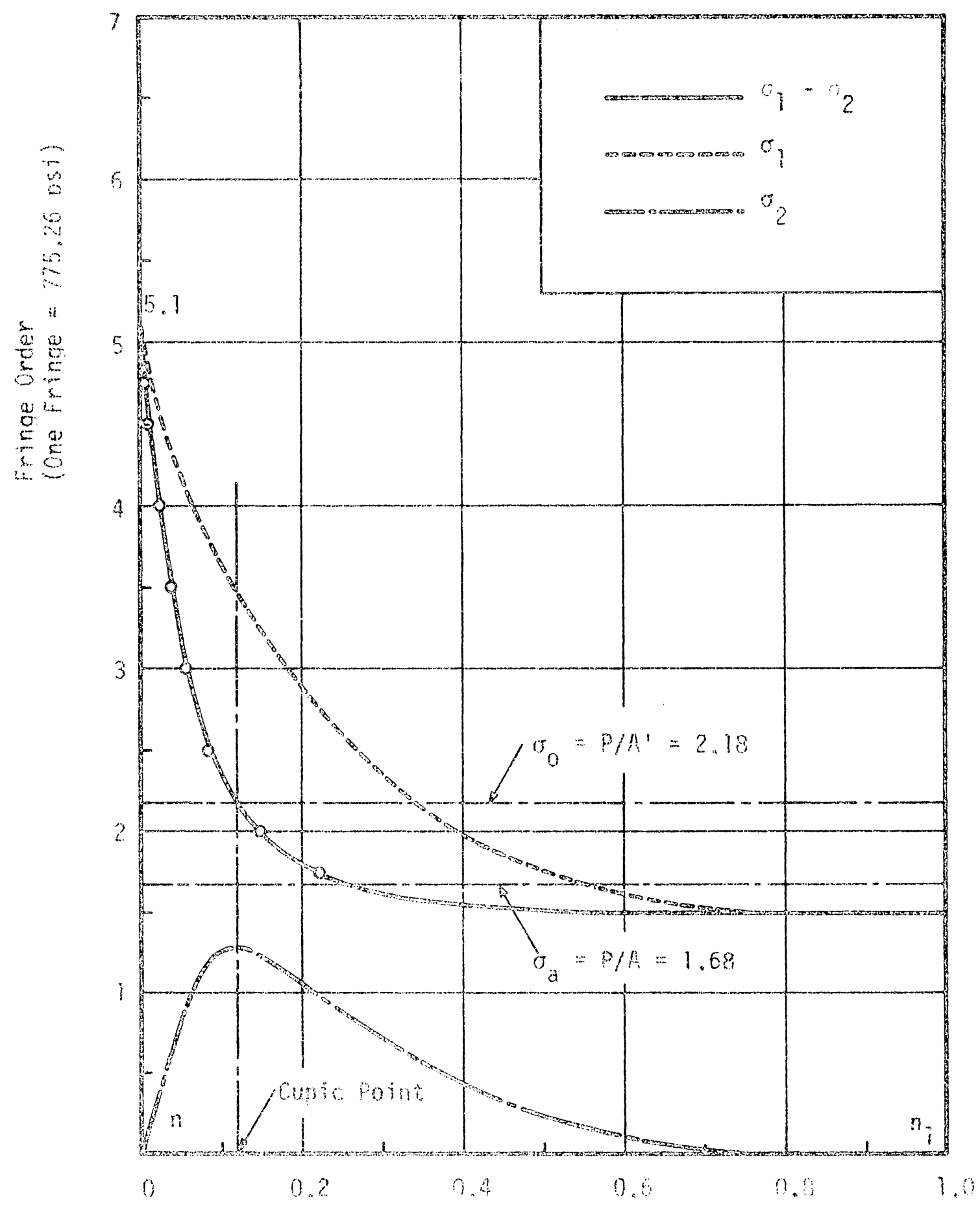

Dinensionless fistance from Hole, $(y-a) /(b-a)$

Fin. 15. Stress Distributions in Snecinen 3 


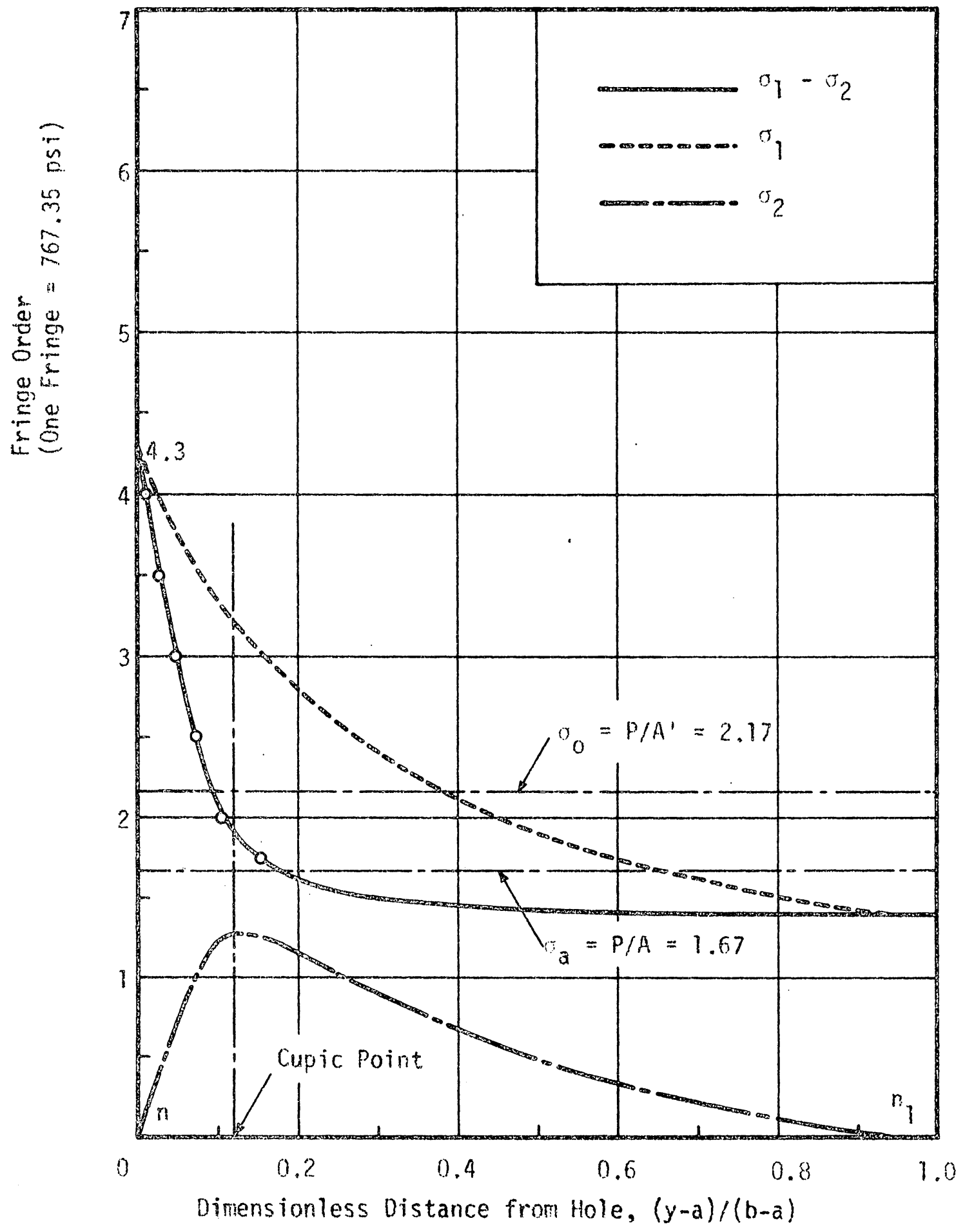

Fig. 16. Stress Distributions in Specimen $\mathrm{C}$ 


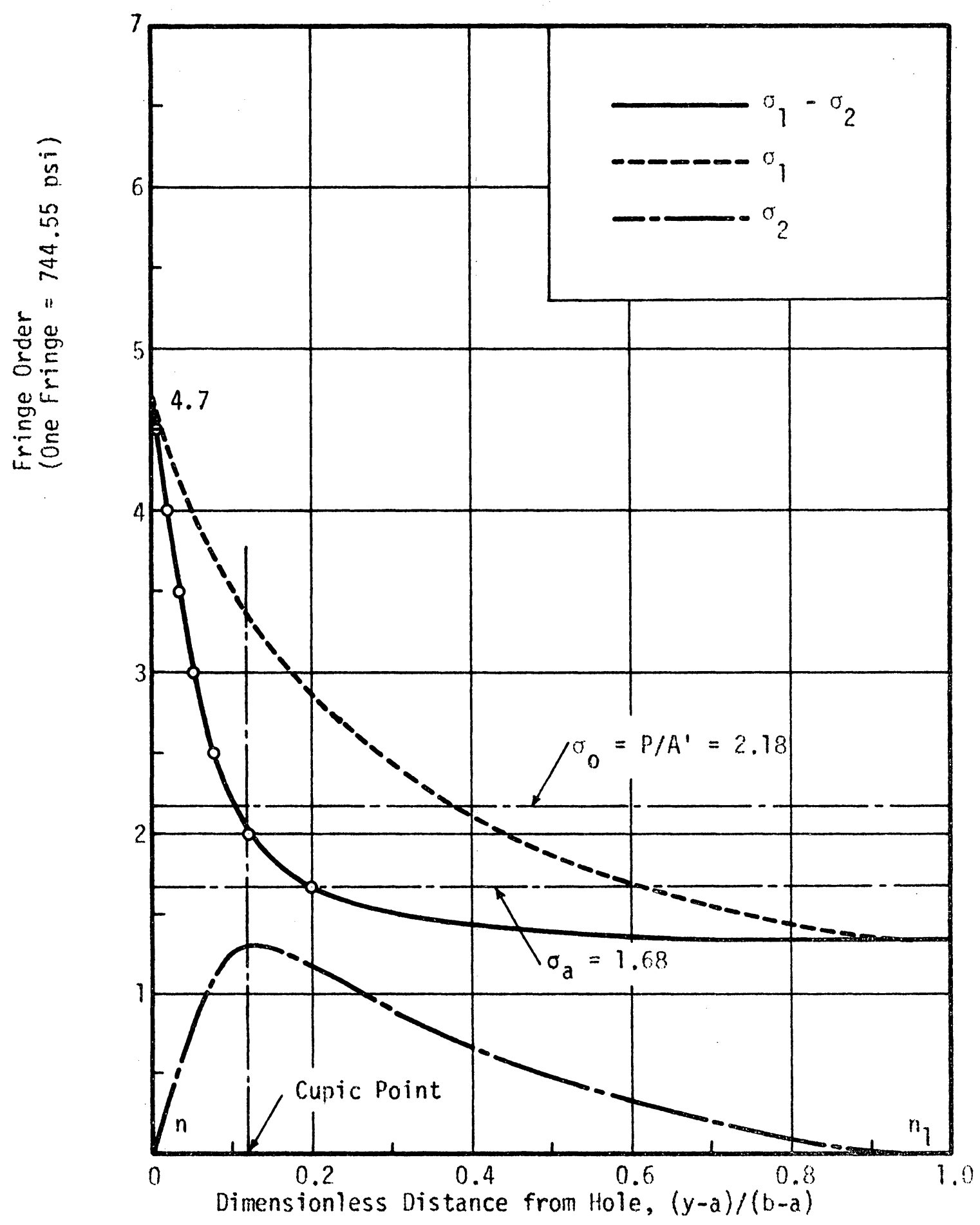

Fig. 17. Stress Distributions in Specimen D 


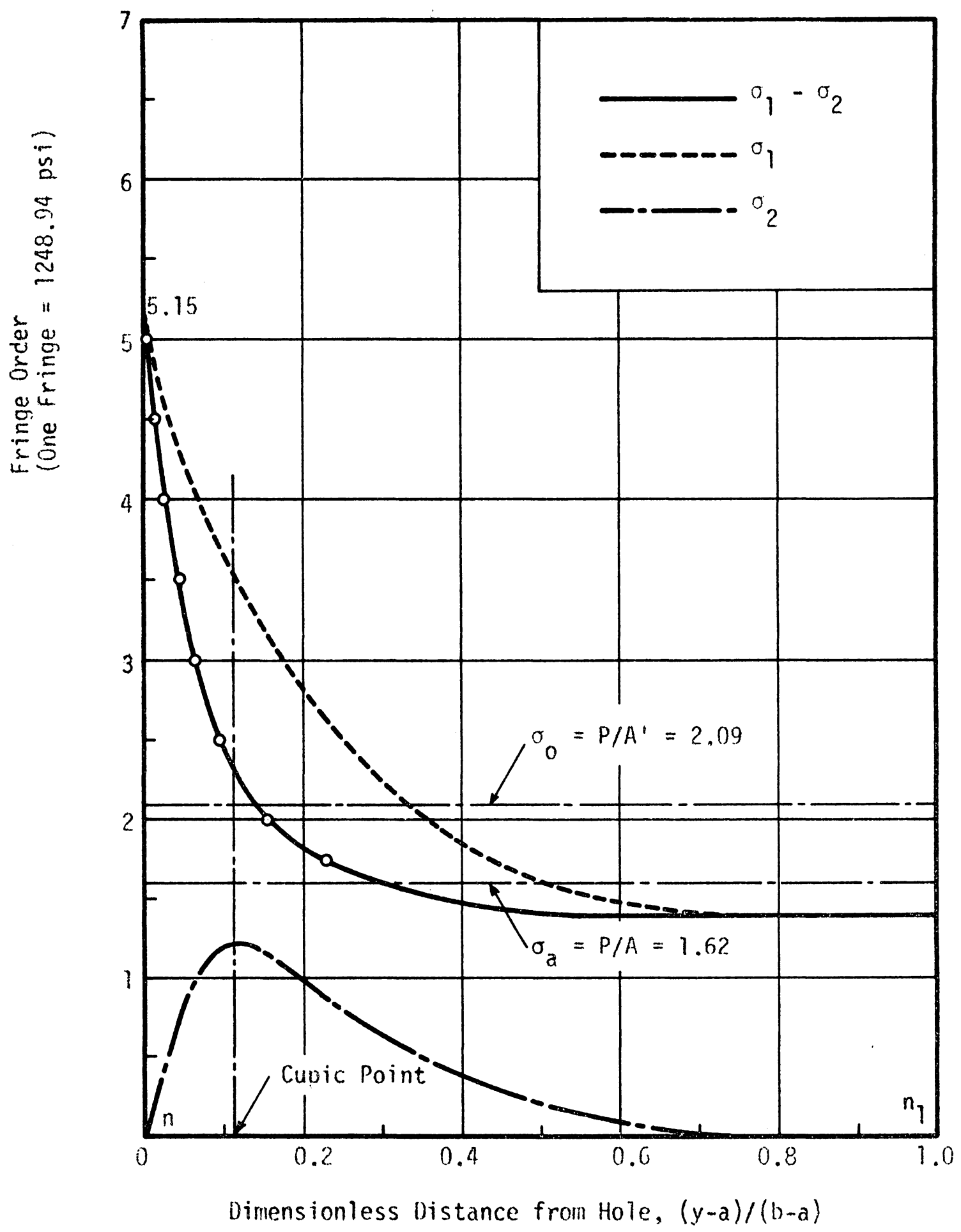

Fig. 18. Stress Distribution in Specimen P 


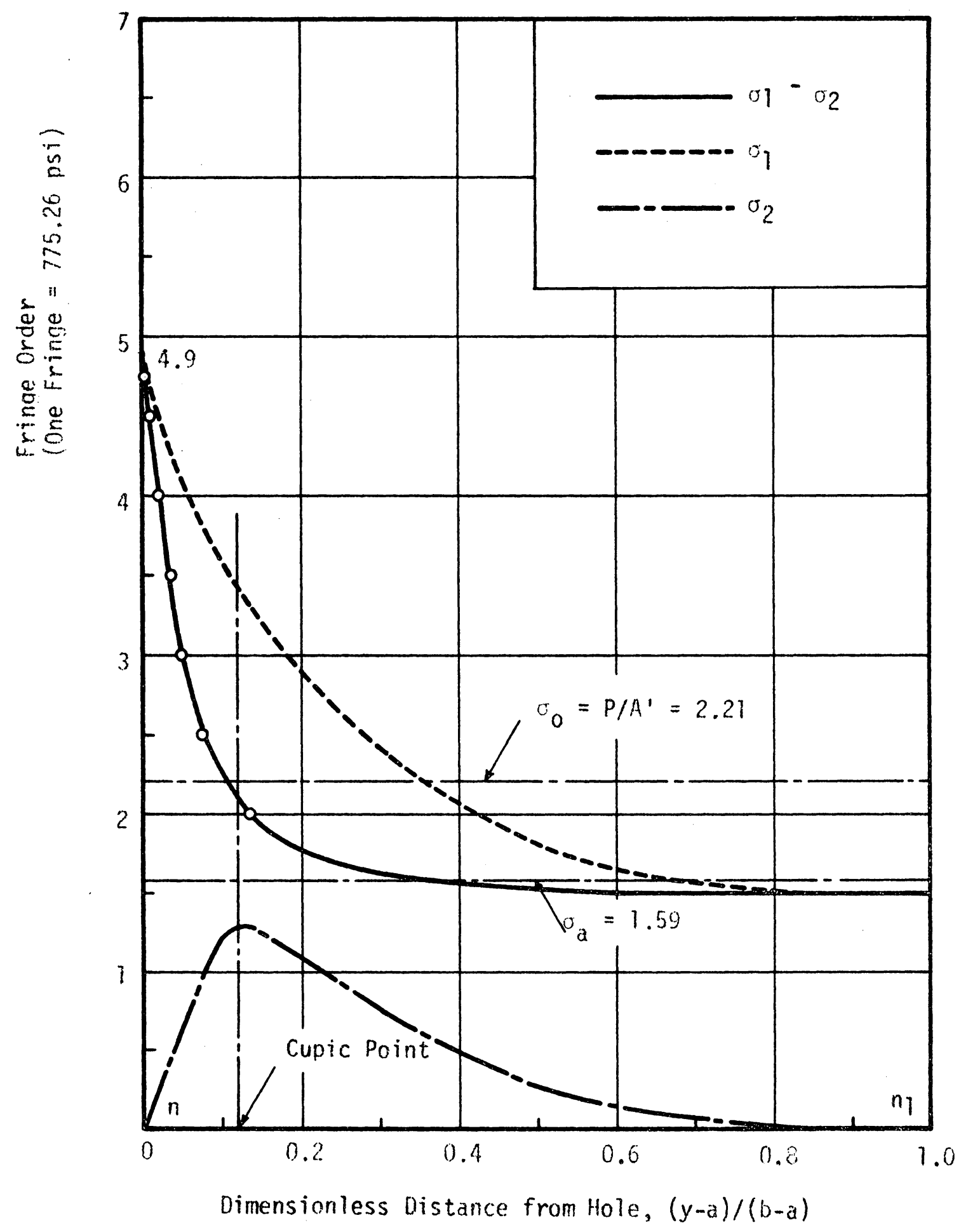

Fig. 19. Stress Distributions in Specimen $A^{\prime}$ 


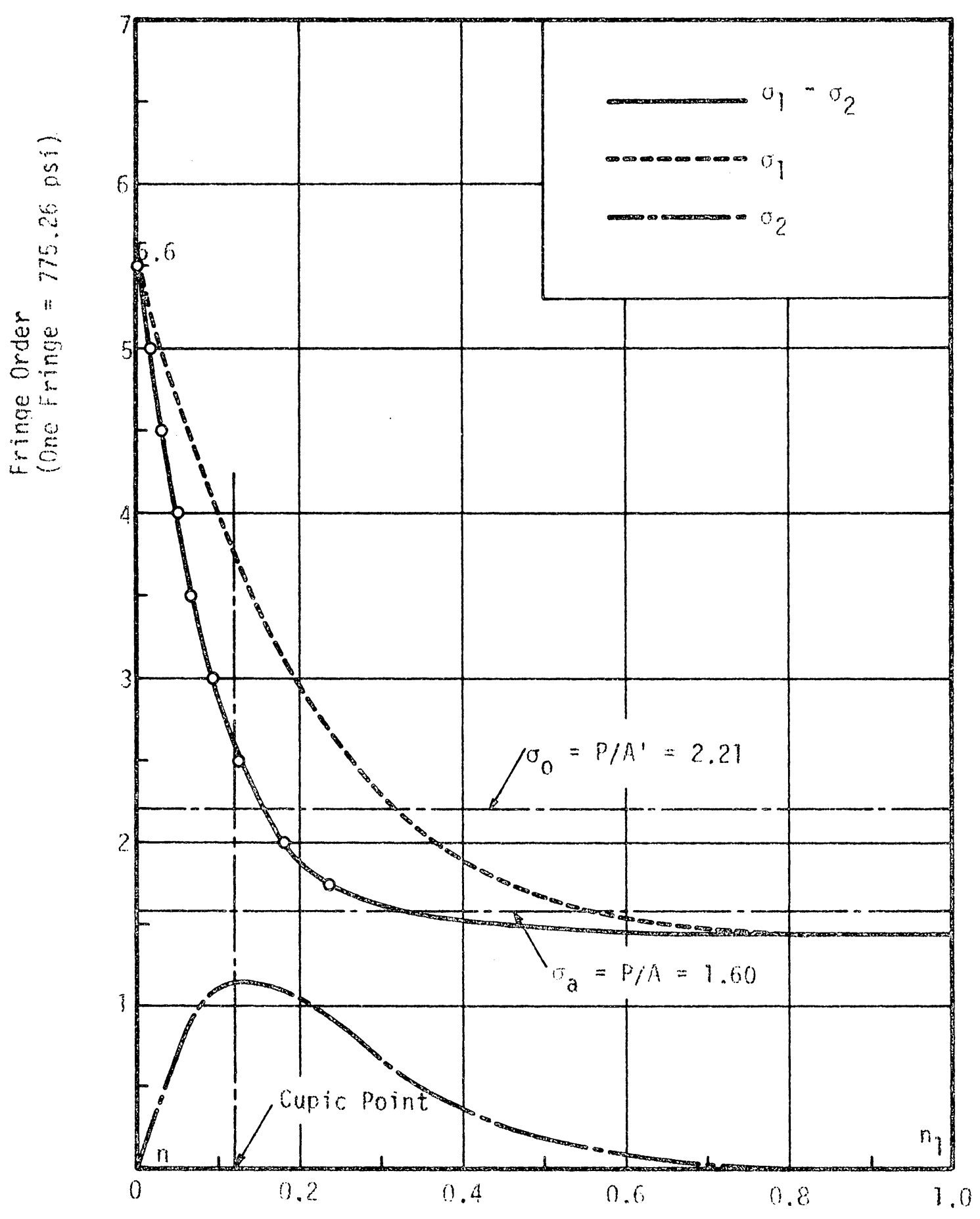

Dimensionless bistance from hole, $(y-a) /(b-a)$

Fig. 20. Stross Distributions in Snecimen B' 


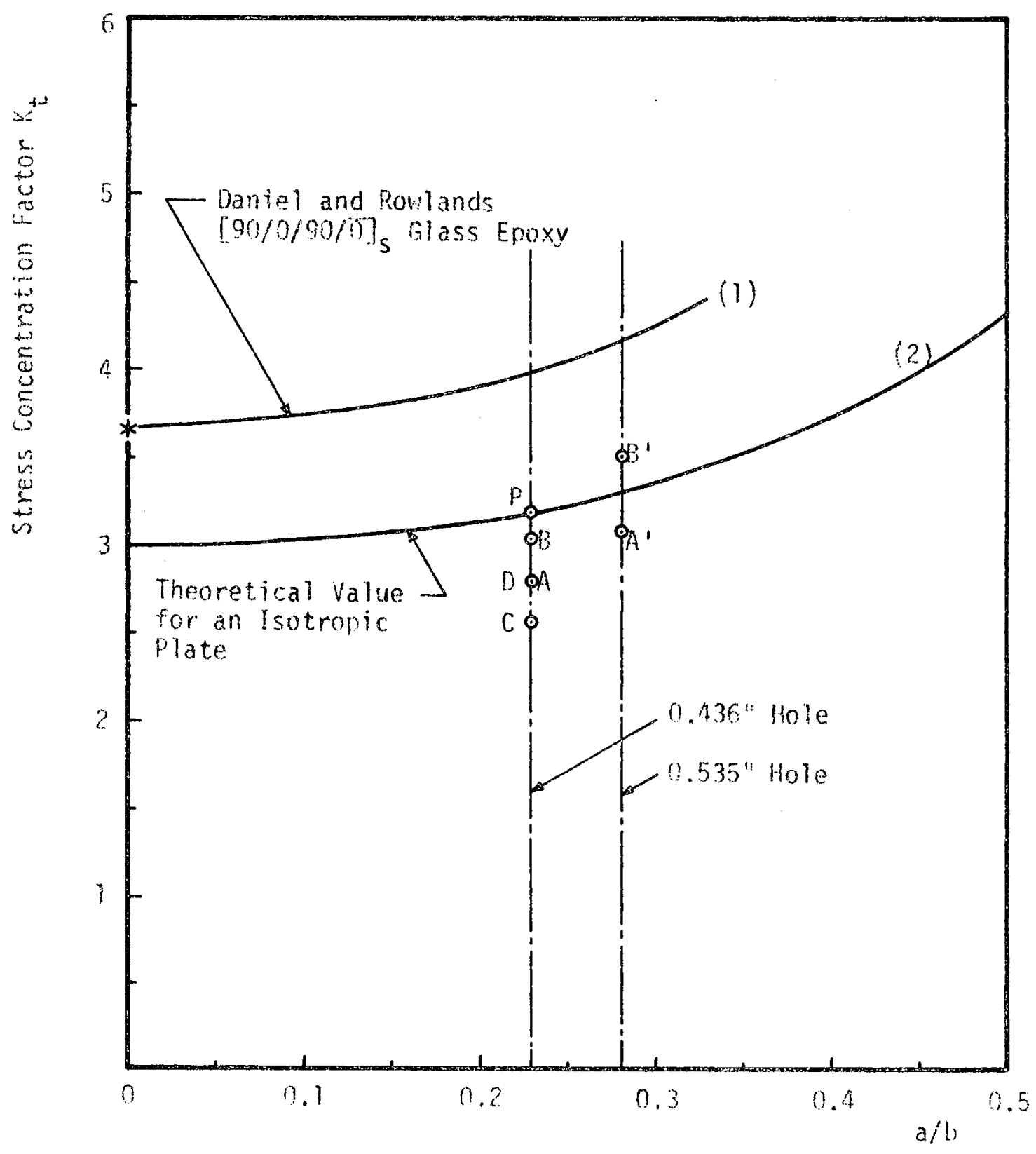

Fia. 21. Comparison with the Experimental Results of Daniel and Rowlands and with the Theoretical Value for an Isotropic Plate 


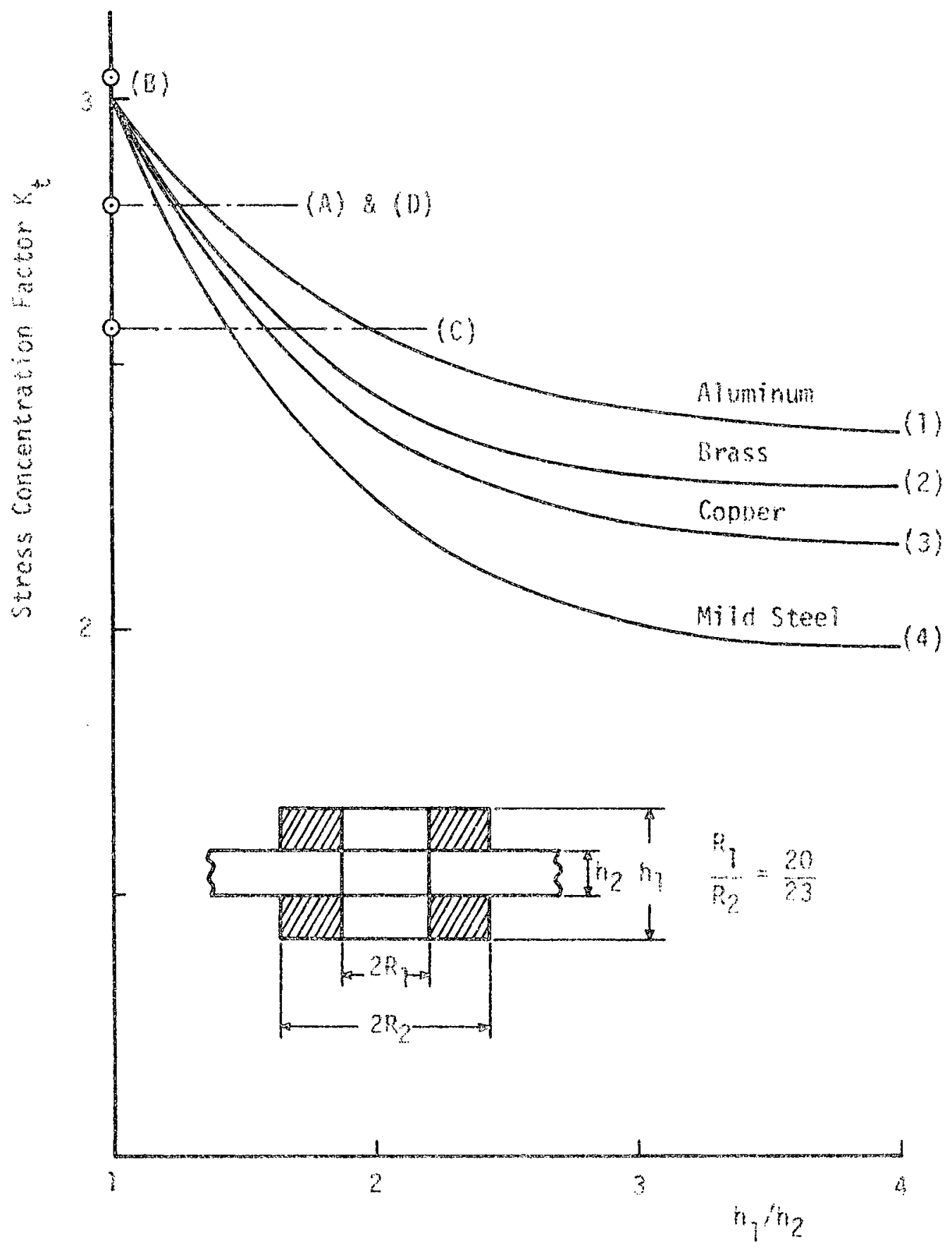

Fin. 22. Comparison with Experinental Results of Suzut: 


\section{The vita has been removed from the scanned document}


ALLEVIATRON OF STRESS CONCENTRATION WITH ANALOGUE REINFORCEMENT by

Toshiaki Chiba

(ABSTRACT)

In order to reduce the stress concentration around a hole in a plate, new, "analogue" reinforcements instead of reinforcing rings were used in this investigation. In two of these specimens, reinforcements with different volume fractions were arranged to coincide with the stress trajectories for an infinite plate with a hole under uniaxial tension. Two ocher specimens contained straight rectangular-grid type reinforcements with different yolume fractions. These 0.005 in. thick brass reinforcements were made by using a photofabrication method. Specimens were then prepared by sandwiching these reinforcements between two epoxy resin places. Plane specimens, i.e., without reinforcement, were aiso made of the same epoxy resin for comparison.

The stress concentrations at the edge of the hole under uniaxial tension were determined by photoeiastic techniques. The measured stress concentration factors were compared with well known values for an infinite, isotropic, hanogeneous plate containing a hole. Results were also compared with published data on [90/0/90/0] 7-ply laminate como posite plates, and on plates strengthened with reinforcing rings.

A definite reduction in stress concentration was observed on specimens containing analoque reinforcement. 